\title{
COURSE DELIVERY METHODS AND INSTRUCTIONAL APPROACH FOR ACADEMIC SUCCESS IN HIGH SCHOOL DISTANCE EDUCATION COURSES
}

\begin{tabular}{c} 
A Dissertation \\
presented to \\
The Faculty of the Graduate School \\
University of Missouri-Columbia \\
in Partial Fulfillment \\
of the Requirement for the Degree \\
Doctor of Education \\
KRISTI D. SMALLEY \\
\hline by
\end{tabular}

Dr. Motoko Akiba, Dissertation Supervisor

December, 2011 
The undersigned, appointed by the dean of the Graduate School, have examined the dissertation entitled

\section{COURSE DELIVERY METHODS AND INSTRUCTIONAL APPROACH FOR} ACADEMIC SUCCESS IN HIGH SCHOOL DISTANCE EDUCATION COURSES

presented by Kristi D. Smalley, a candidate for the degree of doctor of education, and hereby certify that, in their opinion, it is worthy of acceptance.

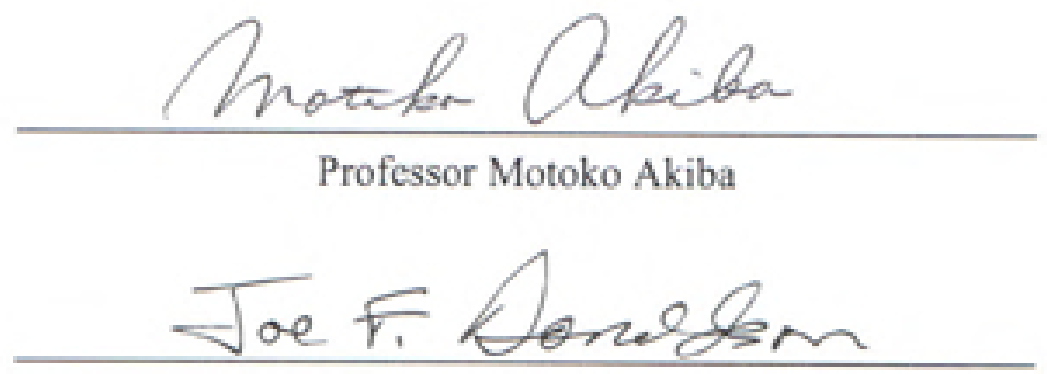

Professor Joe Donaldson
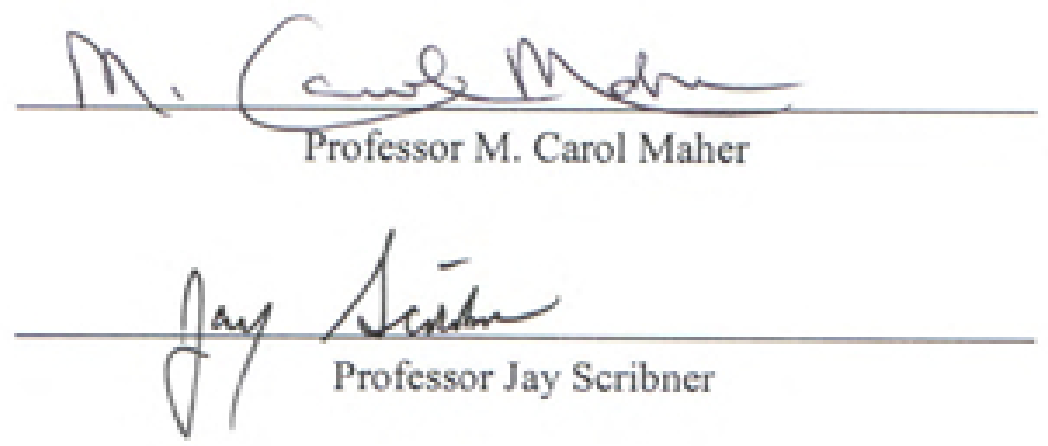


\section{Dedicated to}

All the wonderful teachers I have had throughout my lifetime, beginning with my Mom and Dad, Lila and Jim Curnutte. My “formal education" teachers, including those at Miami R-1 school in

Amoret, Missouri where I was lucky enough to graduate with most of the kids I started kindergarten with.

My family and friends, and my colleagues and co-workers, who supported me in this seemingly never-ending process. Thanks for tolerating my whining and moaning. 


\section{ACKNOWLEDGMENTS}

I would like to thank my advisor, Dr. Motoko Akiba, for her guidance and patience throughout this process. You have been so kind and generous with your

assistance. You are brilliant and a sweet person! I admire that rare combination of qualities in you.

A big thank you also goes to my former boss, Dr. Von Pittman, without whom I would probably have never pursued this venture. I do not know that I will ever be a researcher (this is hard stuff!), but you have taught me the value of doing scholarly research by your example. Thank you for your personal and professional support, and more importantly, for believing in me.

Finally, thank you to my dissertation committee members, Dr. Joe Donaldson, Dr. Carol Maher, and Dr. Jay Scribner for their assistance, time, and guidance. 


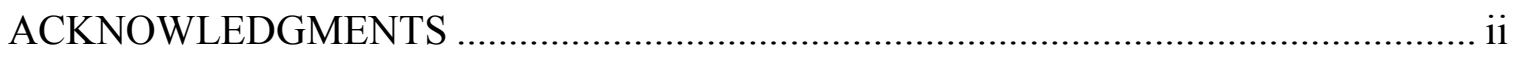

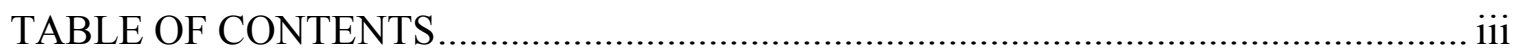

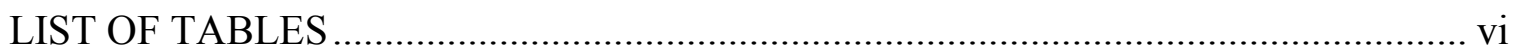

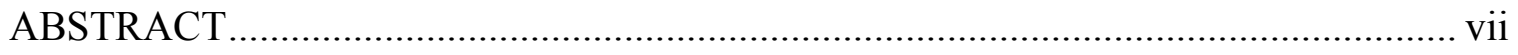

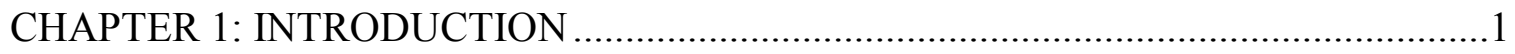

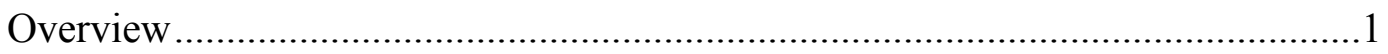

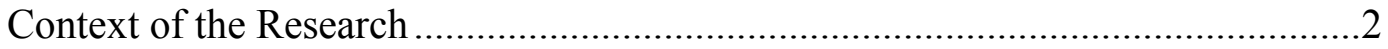

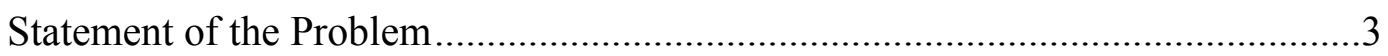

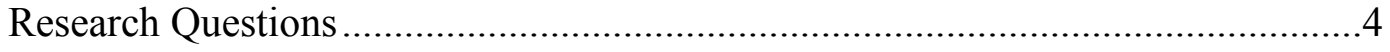

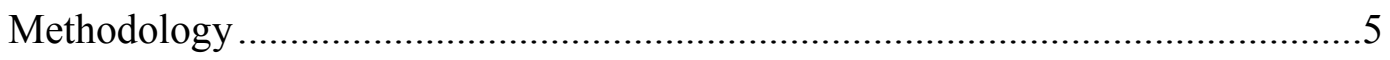

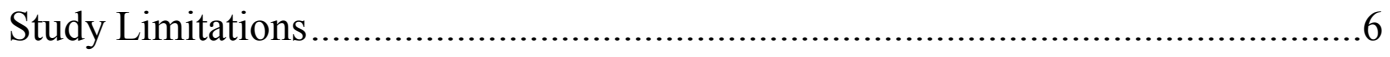

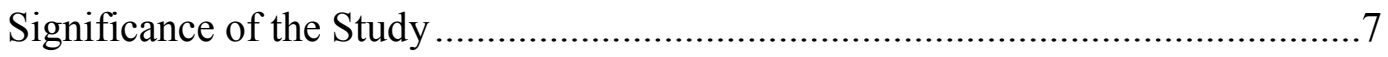

Summary and Overview of the Remaining Chapters ..........................................

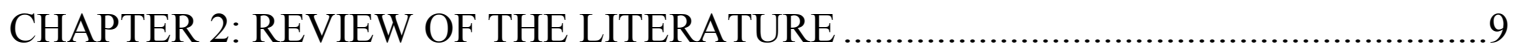

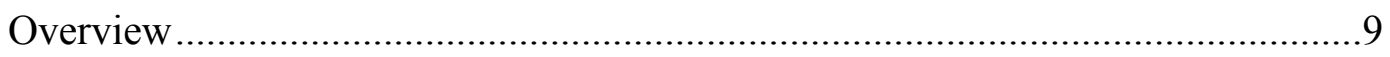

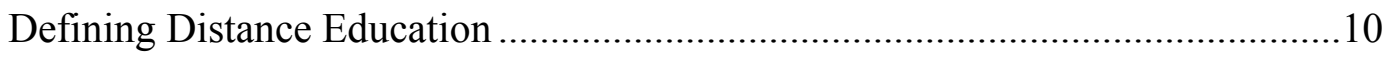

Distance Education and Developments at the High School Level ........................13

Perceived Disadvantages of Distance Education ..................................................15

Advantages and Potential of Distance Education ..................................................17

Empirical Studies on Distance Education Effectiveness ......................................19

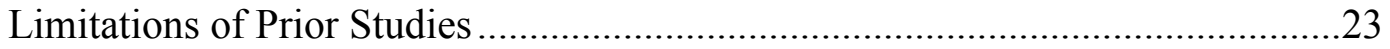


Theoretical Framework

Connecting Theoretical Framework to Students' Online Learning Experiences ..27

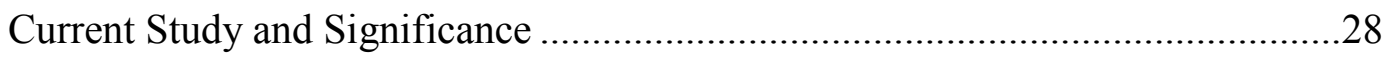

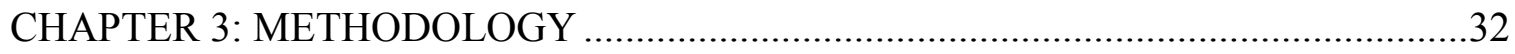

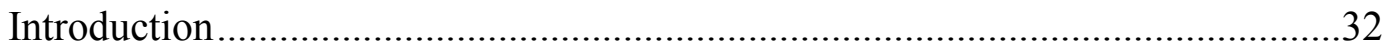

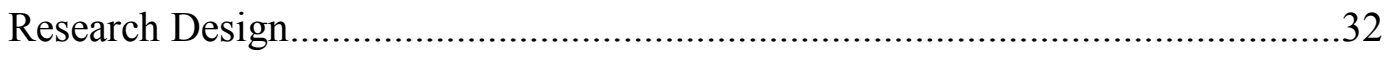

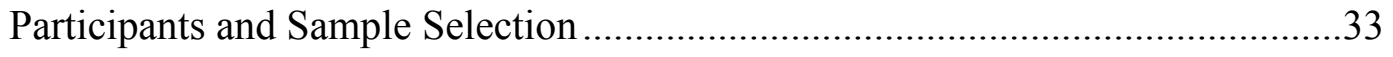

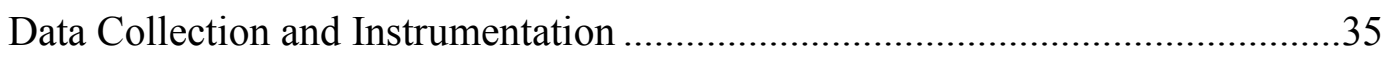

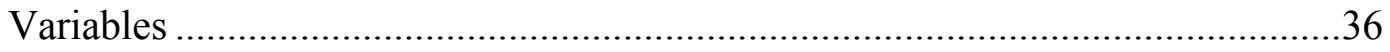

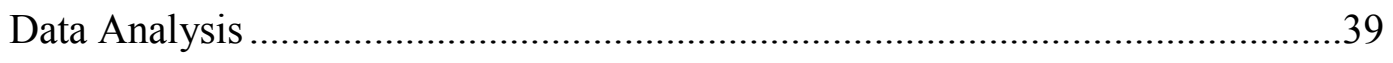

Reliability, Validity, and Pilot Testing .......................................................41

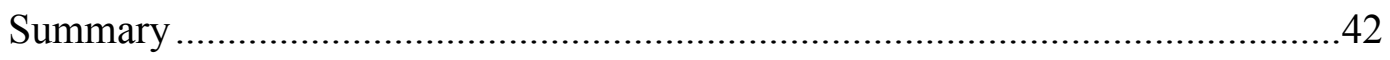

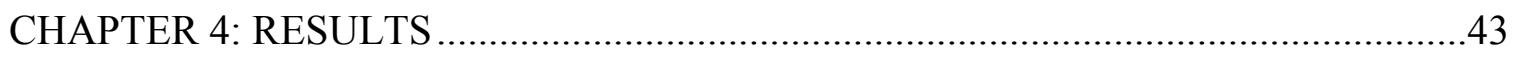

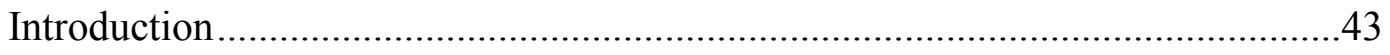

Descriptive Statistics................................................................43

Student Course Experiences by Course Type ..............................................48

Relationship between Course Delivery Method and Student Satisfaction ............52

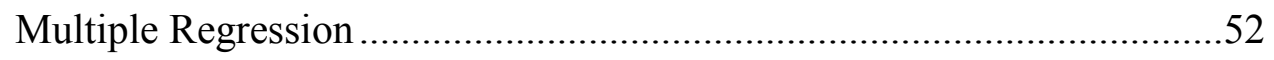

Relationship between Course Delivery Method and Student Achievement ..........54

Course Delivery Method and Student Grades ......................................55

Course Delivery Method and Course Completion Rates ..........................56

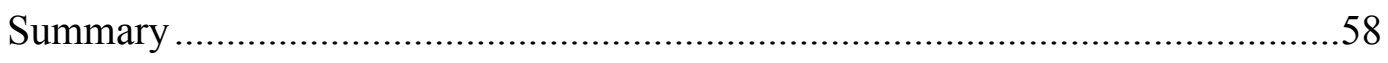


CHAPTER 5: DISCUSSION OF RESULTS ........................................................60

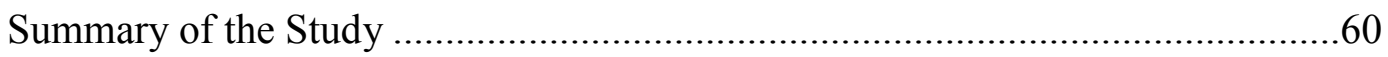

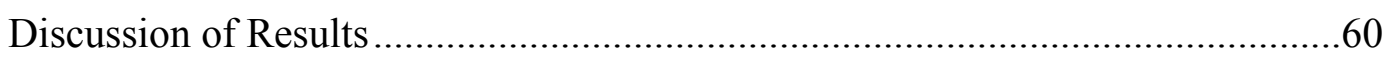

Course Experiences......................................................................61

Course Satisfaction ....................................................................62

Student Achievement: Course Grades \& Completion Rates ...................64

Implications for Theory and Practice.......................................................6

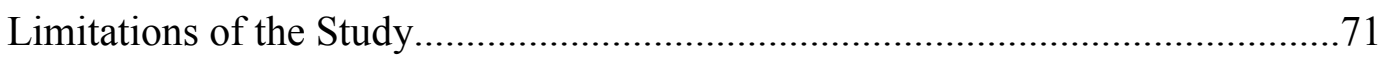

Recommendations for Future Research ..................................................... 73

Recommendations for Leadership Practice .................................................... 74

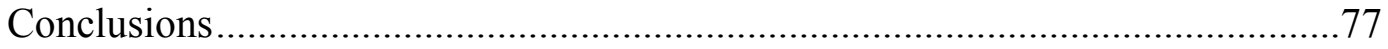

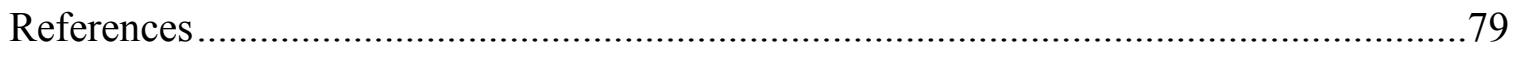

Appendix A: Screenshots of Dummy Student Record from MU High's SIS..................85

Appendix B: Survey Consent Letters, Recruiting Message, and Complete Survey ..........88

Appendix C: MU High School Online Course Survey and SIS Data Codebook ............100

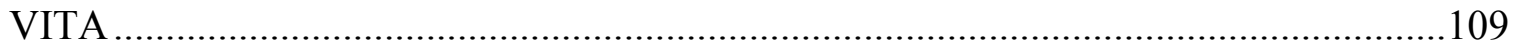




\section{LIST OF TABLES}

Table

1. Learner-Centered Practice Implications for Distance Learning

2. Descriptive Statistics: Student Survey Responses and Characteristics

3. Student Survey Responses and Characteristics by Course Delivery Method

4. Multiple Regression: Relationship between Course Delivery Method and Course Satisfaction Controlling for Student Background Information

5. Multiple Regression: Relationship between Course Delivery Method and Student Grades Controlling for Student Background Information

6. Logistic Regression: Relationship between Course Delivery Method and

Course Completion Rates Controlling for Student Background Information 
COURSE DELIVERY METHODS AND INSTRUCTIONAL APPROACH FOR

ACADEMIC SUCCESS IN HIGH SCHOOL DISTANCE EDUCATION COURSES

\author{
Kristi D. Smalley \\ Dr. Motoko Akiba, Dissertation Supervisor
}

\begin{abstract}
Distance education, especially that of online coursework, is growing at a phenomenal rate. Despite its growth, there is a lack of experimental and quasiexperimental research that has been conducted to investigate what factors influence students' experiences and academic success in online learning environments. Previous research has focused on adult and college level students, or comparing distance education to traditional face-to-face classrooms. This study uses a quasi-experimental design to specifically examine online courses delivered to high school aged students from a distance education program located on the campus of a Midwestern land-grant university. Asynchronous online courses, also called self-paced or independent study courses, were compared to semester-based courses. Semester-based courses in this study had a calendar with a start and ending date, due dates for assignments, and scheduled chats for interaction between other students and the instructor. Asynchronous courses did not have such features. These two types of courses were compared in terms of student experiences, student satisfaction, and academic achievement. The researcher constructed an online survey to gather student perceptions on their experiences and measures of satisfaction, while academic achievement data was gathered from the school's school information system (SIS).
\end{abstract}


Based on the survey data collected from 50 high school students, no significant difference was found in terms of student experiences and satisfaction between students enrolled in asynchronous courses and those in semester-based courses. However, in the analysis of SIS data of 1,207 students, there were statistically significant differences between these two groups when comparing the academic achievement as measured by final course grades and course completion rates. Students in semester-based courses had higher course grades overall. Likewise, students in semester-based courses had a higher completion rate of $86.2 \%$ of students completing their online coursework, while only $62.4 \%$ of their asynchronous counterparts completed their online courses.

Results of this study suggest that some students perform better when given the increased structure and guidance of online courses that are designed in a semester-based format. Although leaders of high school online programs should consider these results and their implications, it is also important to note that students did not perceive differences in their course experiences and satisfaction levels. 


\section{CHAPTER 1: INTRODUCTION}

\section{Overview}

More educational options are available to today's high school students than ever before. While the majority of students complete their secondary education within a traditional brick and mortar school building, some are homeschooled, and others take online courses through a virtual school. Furthermore, many students are piecing together an education through a combination of mixing and matching various educational modalities. With the increasing popularity of distance education coursework at the high school level, including online and virtual courses, I examined if the course delivery methods - whether courses are delivered without a specific timeframe for students to complete them or if they are delivered during semesters as regular schoolsinfluence student outcomes. Specifically, I compared students' course learning experiences, their satisfaction, achievement level, and completion rates between completely asynchronous online courses and semester-based courses.

Chapter One of this study provides background information and context that led to the research problem and specifies the focus of this dissertation research. Research questions, as well as a brief description of the methodology used to investigate those questions, are presented. Then, limitations of prior distance education research are addressed. Finally, the significance of the study, and its implications and applications as it pertains to my distance education institution, the University of Missouri High School, also known as MU High, is discussed. 


\section{Context of the Research}

MU High School is a distance education institution that has historically provided online and correspondence courses to high school students statewide, nationally, and internationally. While most students use MU High's courses as transfer credit on their transcripts at brick and mortar schools, MU High also offers a regionally accredited diploma as an alternative to traditional high school attendance. As the principal of MU High, I sought to examine the academic performance and experiences of students enrolled in our online courses using quantitative research methods.

MU High was formerly part of the University of Missouri's Center for Distance and Independent Study (CDIS), which began offering independent study coursework in 1911. During the summer of 2011, MU High was moved organizationally to the University's College of Education. Independent study (described as an asynchronous course in this study) is a method of distance education delivery whereby students enroll in coursework at any time and work at their own pace. Independent study has its roots in correspondence study, and more recently, the trend has shifted toward e-learning or online course delivery (Edelson \& Pittman, 2001), as will be examined in this research project. Hybrid and blended courses, which combine different modalities, also exist. As its title denotes, the bulk of independent study is done by students who independently progress through coursework by reading assignments, submitting lessons, and taking proctored exams. In the 2008-2009 academic year, MU High School had more than 11,400 course enrollments. Of these, approximately 8,300 enrollments were in online courses. Online course enrollments have outnumbered correspondence course 
enrollments for the last three years. There is every indication this trend will continue, thereby widening the gap between online and correspondence courses.

Independent study offers students a flexible means of completing their education, including the completely asynchronous delivery of instruction. Students can enroll at any time of the year, and within minimum and maximum lesson submission and course completion guidelines, can work at their own pace. Independent study increases student accessibility to coursework that may not be available to them otherwise. For example, students take MU High School courses because of scheduling problems, limited course availability, credit recovery purposes, or to graduate early. While it allows for a great deal of flexibility, independent study is not an ideal match for all students. Some students say they desire or need more structure and oversight, greater interactions with their instructors and fellow students, and a schedule to keep them on track. Hence, in addition to the more than 150 asynchronous courses MU High currently offers, we also started offering a select few of what we call "semester-based" courses in 2007. Hoping to provide students with the structure they seem to desire, these semester-based courses have starting and ending dates, scheduled chats between instructors and students, e-mail, discussion forums, and assignments due on a weekly basis.

\section{Statement of the Problem}

With the increasing popularity of such courses, I wished to understand if students are being adequately served and their educational needs were being met by online instruction and interaction with their instructor and peers. For example, I wanted to know how well students perform academically, and how satisfied they were with their online 
learning experiences. By doing so, I sought to gain knowledge that should improve my performance as an instructional leader. Information obtained from such a study should help improve the quality of our services to students, in addition to facilitating decisionmaking for how my school should allocate its personnel and monetary resources.

\section{Research Questions}

For this quantitative study, I posed three research questions relating to online courses students take through MU High:

- $\quad$ Research Question 1: How do learning experiences of high school students in semester-based courses differ from those of students in asynchronous courses?

- $\quad$ Research Question 2: Are students in semester-based online courses more satisfied with their course experience than the students in asynchronous online courses?

- $\quad$ Research Question 3: Do students in semester-based online courses perform better and have a higher completion rate than students enrolled in asynchronous online courses, controlling for previous online course experience and student gender? 


\section{Methodology}

I used a quasi-experimental research design with an online survey and data from MU High's student information system (SIS) database, as will be explained in greater detail within Chapter Three. I developed an online student survey to examine students' online course experience and satisfaction, while the SIS provided enrollment records, final course grades as a measure of student achievement, and records on course withdrawal or completion. A survey instrument is useful "to collect information from or about people to describe, compare, or explain their knowledge, feelings, values, and behavior" (Fink, 2006, p. 1), and it was necessary for me to develop my own survey to collect information not available through course evaluations or the SIS.

I chose to use quantitative methods because of the nature of my research questions for examining the effects of course delivery methods on student outcomes. In addition, quantitative data is easily available and procedures are already in place to gather and record data through the SIS at my institution, which was another contributing factor in my selection of quantitative rather than qualitative methods. This numeric data was combined with the quantitative data I collected through an online student survey. I used Statistical Package for the Social Sciences (SPSS) 19 to manage and analyze these quantitative data. 


\section{Study Limitations}

This study has several limitations. First, students self-selected the subjects in which they choose to enroll, as well as the method of course delivery (asynchronous vs. semester-based). Students will have preferences, individual learning styles, motivating factors, and other differences that will affect the courses in which they choose to enroll. These factors also influence course completion rates. Because of self-selection, the study cannot be considered a randomized field experiment, often considered the "gold standard" for "research design for assessing causal effects" (Rossi, Lipsey, \& Freeman, 2004, p. 237). As Rossi et al. explain, my research design was a nonrandomized quasiexperimental design because the participants were not randomly assigned like what is required for a true experimental design. Since enrolled students self-selected their participation, my study contained some degree of selection bias (Rossi et al.).

Other limitations included a small sample size for students enrolled in semesterbased courses. Up to this point, the numbers have been small because these are new courses for MU High School. Also, the specific locale and context associated with MU High may limit the study's generalizability, or its applicability to other situations (Merriam, 1998). For example, as far as I know, MU High is the only university sponsored independent study program that is offering semester-based online courses for high school students. The potential for researcher bias exists because the researcher is employed by the institution involved in the study. Additionally, not knowing students' previous academic performance is another possible limitation. Lastly, final course grades 
are not always a good indicator of how much a student does actually learn, but as in this case, may be used as a measurement of comparison.

\section{Significance of the Study}

This research project will overcome some of the limitations of prior distance education research. For example, it used a quasi-experimental design and focused on high school students. Since very little research has been done comparing different methods of course delivery in high school online courses, this study adds to the experimental or quasi-experimental research knowledge base that should help guide leaders of online high schools in identifying best practices, especially when it comes to course delivery methods.

Leaders of online schools can then use the information produced by the study to help them in planning and allocating resources such as personnel, time, and money. For example, private schools that do not receive any tax dollars or other types of subsidies should consider expenses versus revenues of any course offerings. Coupled with this consideration is whether or not students will pay tuition to enroll in courses. Questions leaders should consider include "where are these students going to come from" and "how can we make our courses attractive to them". Also, it is important to consider staffing needs. Leaders of online schools need to consider if it is worth the time and expense to have two separate product lines (asynchronous and semester-based courses), and do they have the instructional design and teaching staff to support continued course offerings. 
The ultimate goal, however, is to improve student achievement and their experiences while enrolled in online coursework.

\section{Summary and Overview of the Remaining Chapters}

In summary, this research examined the effectiveness of online instructional methods and course delivery mechanisms and their effects on student achievement. While this first chapter gave a broad introduction, subsequent chapters will provide greater details about the study. Chapter Two presents a synthesis of relevant literature pertaining to distance education in general and its historical developments. Definitions of terms are incorporated into the literature review. Limitations of the prior studies are discussed, along with an explanation of how the study hopes to overcome such limitations. Chapter Three provides the details on the study's methods including data collection and analysis. Chapter Four presents the results of data analyses as they relate to the study's research questions, while Chapter Five discusses those results and their implications for future research and leaders of distance learning institutions. 


\section{CHAPTER 2: REVIEW OF THE LITERATURE}

\section{Overview}

A review of literature on distance education generally, and then more specifically online course delivery, is presented in this chapter. Because many of the terms used are specific to distance education, explanations are presented for each of the following elements: distance learning/distance education; independent study; correspondence study; online, e-, and virtual learning; synchronous; and asynchronous as they relate to distance education. It should be noted that some terms are used interchangeably, but there is often disagreement within the field of distance education regarding the subtleties and nuances of terminology.

The history of distance learning in the United States is briefly reviewed, as well as the benefits distance education affords. Because distance education offers flexible learning opportunities to fulfill a variety of needs, the potential advantages of learning at a distance are presented, along with counterpoints addressing criticisms and concerns. This background literature will be followed by a thorough review of empirical studies that examined the effectiveness of distance education and the discussions of the limitations of these empirical studies. This literature review concludes with a presentation of a theoretical framework that guides the current study, and then how this study

overcomes the limitations of prior empirical studies on the effectiveness of distance education. 


\section{Defining Distance Education}

Distance education as a term first appeared in an 1892 University of Wisconsin catalog (LeBaron \& Tello, 1998). At that time, distance education consisted of correspondence study

only. Today, considerable disagreement exists concerning what exactly distance education is, and various definitions may or may not include bounding by location, time, and method of course delivery. Concentrating strictly on location, Kirby (1998) defines distance education "as an educational transaction between a teacher at one geographic location and a student at another" (accessed March 20, 2009, at http://www.westga.edu/ distance/ojdla/summer12/kirby12.pdf ).

A more encompassing definition is one that describes distance education as instruction that occurs when the student and instructor are separated by distance, time, or both (Mupinga, 2005). Also taking a broader perspective, the United States Distance Learning Association defines distance education as the "acquisition of knowledge and skills through mediated information and instruction, encompassing all technologies and other forms of learning at a distance" (accessed February 9, 2010, at http://www.usdla.org/html/aboutUs/vmd.htm).

As noted above, correspondence study, or learning via postal mail, was the first form of distance education (Bower \& Hardy, 2004). In correspondence study, students complete assignments and send them to an instructor. Although the earliest forms of correspondence study occurred through the mail, it was later expanded to include instruction through other mediums such as telephone, audio, and CD-ROM (Mupinga, 
2005; Schlosser, 1996). Gradually, a new term, independent study, emerged. Independent study has been used since the 1960s to refer to correspondence, and now is also being used to describe some models of online instructional delivery (Barbour \& Reeves, 2009).

Perhaps the greatest disagreement on distance education terminology is associated with the inter-related and often used interchangeably, terms of online learning, e-learning, and virtual learning. Watson, Winograd, and Kalmon (2004) defined online learning as "education in which instruction and content are delivered primarily via the Internet" ( $\mathrm{p}$. 95). Mupinga (2005) describes virtual learning as being delivered by the Web and often utilizing a learning management system. By doing so, students can complete their education solely on the Internet without ever physically stepping foot into a classroom. While many students take online courses to supplement a brick and mortar education, in a virtual school, the entire student body has access to online courses (Mupinga, 2005).

Different forms of distance learning may also be classified by timing of content delivery. In a black and white world, there are two opposite sides of the spectrum: synchronous and asynchronous. Synchronous learning occurs with real time communication between the instructor and students (Rice, 2006). Examples of synchronous learning include students meeting in a traditional classroom with a teacher during a specified class period, and participants engaging in videoconferencing. Conversely, asynchronous delivery occurs when students enroll in coursework at any time and work at their own pace, usually within specified time guidelines (Edelson \& Pittman, 2001). In asynchronous courses, students progress through coursework often without meeting their classmates and instructor in real time (Edelson \& Pittman, 2001; Rice, 2006). Examples of asynchronous courses include what are referred to as 
correspondence and independent study courses. Hybrid distance learning courses, which incorporate both synchronous and asynchronous elements, make it difficult to classify a given course as one or the other. Undoubtedly, the lines will continue to blur as distance learning becomes more prevalent, and traditional classrooms increasingly incorporate aspects of distance learning environments.

In this study, I examined students' experiences and satisfaction with courses, and their achievement level and completion rates in completely asynchronous online independent study courses compared to those enrolled in comparable online courses with a semester calendar, scheduled assignments, and synchronous elements such as scheduled chat room discussions between instructors and fellow students. For this study, an asynchronous course will be those online independent study courses where students can enroll at any time and work at their own pace. Students do not have any real time interaction with their instructor or other students. For these asynchronous courses at MU High School, students can complete a half unit course (equivalent to a semester in a regular classroom) anywhere from six weeks to nine months from their date of enrollment. The other comparison group will consist of students enrolled in semesterbased courses. For this study, online semester-based courses at MU High School have a start date, an end date, due dates for assignments and exams, and real time interaction between students and their instructor. Semester-based courses roughly follow an academic calendar. Side by side comparisons of such facets of online course delivery have not been made, as the bulk of online course research done at the high school level has made comparisons with traditional face to face classroom instruction. 


\section{Distance Education and Developments at the High School Level}

High school independent study most likely began on college campuses. Welch (1993) notes “in 1992, 32 of the 83 National University Continuing Education Association (NUCEA) Independent Study member institutions offered correspondence high school programs. Notable among these are Brigham Young University, University of California, Indiana University, University of Missouri, and University of Nebraska. States which have established complete secondary correspondence schools include Alaska and North Dakota” (p. 7).

The University of Nebraska's Extension Division paved the way for universitybased high school independent study programs with the opening of its Independent Study High School in 1929. This program served students in the state, nationally, and even internationally. It began offering high school diplomas in 1967 (Smalley, 2005). In 1997, James Van Arsdall at Nebraska wrote a historical dissertation on the high school independent study prototype (Pittman, 2003).

Although the University of Missouri's independent study program offered high school level courses at least as far back as 1913, these courses were largely aimed at making students admissible into the University and to train students to become school teachers. MU High School at Missouri's Center for Distance and Independent Study became regionally accredited as a diploma granting institution in 1999, more than 30 years after Nebraska’s Independent Study High School (Smalley, 2005).

Beyond the university-based programs, some of the longest established and most successful virtual schools include the Virtual High School in Massachusetts, 
CyberSchool of Eugene, Oregon, the Florida Virtual School, and Apex Learning which specializes in Advanced Placement courses (Barbour \& Reeves, 2009; Mupinga, 2005; Rice, 2006; Zucker \& Kozma, 2003). Virtual or online schools also include state sponsored programs, cyber charter schools, programs at the school district level, and private for-profit agents such as K12 and Connections Academy (Barbour \& Reeves, 2009; Cavanaugh et al., 2009; Roblyer \& Marshall, 2003; Rice, 2006; Zucker \& Kozma, 2003).

The Sloan Consortium survey of school administrators found school districts usually depend on multiple learning providers, including postsecondary institutions (46.5\%), state virtual schools within their home state (40.7\%), independent vendors (34.7\%), and education service agencies (28.9\%) (Picciano \& Seaman, 2009). The school administrators survey also found more than $70 \%$ of randomly selected schools had one or more students enrolled in a fully online course, and $41 \%$ had one or more students enrolled in a blended or hybrid course. Some school districts are also now developing and offering their own online courses (Picciano \& Seaman, 2009).

In 2006, Michigan passed a state law requiring that students graduating from high school have at least one online learning experience (Davis, 2009), and likewise, Alabama is the second state to follow suit with its 2009-2010 entering freshman class (Alabama Department of Education, 2009, accessed January 8, 2009 at https://docs.alsde.edu/documents/61/OnlineGuidance.pdf).

A report on K-12 virtual schools estimated that over one million students took online coursework in 2007-2008, an increase of 47\% since the 2005-2006 school year (Davis, 2009; Picciano \& Seaman, 2009). This number is expected to only increase, as is 
reflected by the also increasing number of state-wide K-12 virtual school programs. These numbers are continuing to rise so that schools may increase curricular options for their students, ease scheduling and staffing concerns, teach students technological skills, and better prepare students for college level coursework, which is also seeing a rise in online enrollments.

\section{Perceived Disadvantages of Distance Education}

Despite studies supporting distance education's value, a considerable lack of support and skepticism continues to exist. Support for distance learning methods may be low from some educational stakeholders because of a lack of technological expertise by school personnel (Bower \& Hardy, 2004; Mupinga, 2005). Furthermore, some faculty members question the academic legitimacy and rigor of electronic instruction (LeBaron \& Tello, 1998). Educator buy-in is important in establishing distance learning programs, and without it, some barriers only become more difficult to overcome. Additional barriers to schools offering distance education courses include concerns over course quality, development costs, payment of fees to outside providers, and potential loss of revenue because of per student state funding policies (Barbour \& Reeves, 2009; Picciano \& Seaman, 2009). Many educators are concerned about the lack of socialization by students, lack of face to face interaction between students and teachers, and other possible communication challenges that may result from distance learning methods (Davis, 2009; Mupinga, 2005; O’Neal, 2009; Sher, 2008; Welch, 1993). 
Because distance learning today often requires a computer and internet access, there is also concern that it is more difficult for poor and disadvantaged students to reap its benefits. Indeed, some educators question whether the "digital divide" actually increases access to coursework, or does it widen the gap between the haves and have not's further (Cavanaugh et al., 2009; Zucker \& Kozma, 2003). Also a concern, especially for at risk students, is the low retention rate because of the number of distance education students that drop out of distance education courses at all levels (Barbour \& Reeves, 2009; Zucker \& Kozma, 2003). For example, Zucker and Kozma (2003) found a higher percentage of online students not completing or dropping online courses compared to similar face to face courses at all levels of education. Other studies have also noted challenges to distance education retention rates (Barbour \& Reeves, 2009). Furthermore, some schools may use online classes as a dumping ground for disruptive or poor performing students in an effort to remove them from the classroom (Mupinga, 2005).

Finally, distance education and online courses may not be a good match for everyone, especially those learners who do not have good computer skills (Thomas, 2008). Simply put, different students have different learning styles that work best for them, and hence, some students are more comfortable or prefer learning in a traditional classroom setting as opposed to a distance or online environment (Hannay \& Newvine, 2006; Schlosser, 1996). Moore and Thompson (1990) further explain that "research is likely to show that there are individual learner differences in response to distance education and its various techniques, as there are to classroom instruction, to particular teaching styles, even to particular teachers" (p. 37). 


\section{Advantages and Potential of Distance Education}

Realizing that distance education may not be a good match for all students, as is the case with any single form of learning, there are many advantages and benefits to be gained from it. Foremost among distance education's benefits is its extremely flexible nature. Distance learning allows for flexible scheduling free of class, time, and location restrictions (Barbour \& Reeves, 2009; Bower \& Hardy, 2004; Cavanaugh et al., 2009; Mupinga, 2005; Rice, 2006). Such flexibility and convenience allows nontraditional and adult students, especially those with family responsibilities, to attend school without quitting their jobs (Bower \& Hardy, 2004; Nasseh, 1997). Distance learning can be used to supplement homeschooling or a traditional education, for homebound students, or for athletes and entertainers whose schedules prevent traditional school attendance (Rice, 2006; Smalley, 2005).

In addition to removing time boundaries, distance education helps remove access and location boundaries to learning. Surveys of schools indicate that counselors frequently recommend correspondence courses for meeting such needs as expanding and enriching existing school curricula (Welch, 1993). For example, rural and remote schools are able to expand learning opportunities for students, and often help keep the school

itself operational (Kachel, Henry, \& Keller, 2005; Picciano \& Seaman, 2009; Thomas, 2008). Distance education provides more equitable access to curriculum by providing additional course options and educational choice, and often at reduced costs to schools.

Other cost saving aspects of high school distance education courses include the potential sharing of resources, earning college credit early through such means as 
Advanced Placement and dual credit options, reducing drop-out rates, and accelerating the completion of graduation requirements (Rice, 2009). Distance education can be used by administrators to combat staffing shortages and overcrowded classrooms at colleges and schools (Barbour \& Reeves, 2009; Cavanaugh et al., 2009; Hannay \& Newvine, 2006; Kirby, 1998; Mupinga, 2005; Zucker \& Kozma, 2003). In summary, distance education coursework provides opportunities to those who may not have other educational options (Moore \& Thompson, 1990).

For many students, distance education may offer intrinsic and intangible benefits beyond acquiring academic content. High ability students often choose and do well in online courses, but students who are struggling or need credit recovery are also increasingly choosing online coursework for a variety of reasons (Barbour \& Reeves, 2009; Cavanaugh et al., 2009; Davis, 2009; Rice, 2006; Picciano \& Seaman, 2009). Attributes of successful distance learning can include the teaching of important life skills such as motivation, goal-setting, persistence, self-reflection, ability to work independently, computer and technology skills, and organization and time management skills (Kachel et al., 2005; Rice, 2006; Thomas, 2008; U.S. Department of Education, 2009; Welch, 1993; Zucker \& Kozma, 2003). A study by Dodd, Kirby, Seifert, and Sharpe (2009) found students with high school distance education experience were more likely to persist beyond their first year of college attendance and performed better in their first year of college compared to those students with no distance learning experience. Additionally, some students prefer distance education courses because they are allowed to study in familiar surroundings with increased privacy and fewer distractions (Moore \& Thompson, 1990). 


\section{Empirical Studies on Distance Education Effectiveness}

Examination of prior research literature uncovered two types of studies on distance education: 1) effects of distance education on student achievement and 2) studies of student perceptions of and satisfaction with distance education. In general, however, few studies on distance education at the high school level were published compared to those done at the post-secondary level. Furthermore, there is a lack of focus in comparing different distance education delivery methods.

Many meta-analyses of distance education effectiveness have been conducted so far, yet few of them have separated the findings for post-secondary and secondary schools. Shachar and Neumann (2003) analyzed 86 experimental and quasi-experimental studies completed between 1990 and 2002 to compare the academic performances of distance and traditional education students. Their meta-analysis showed that students in distance education academically outperformed their face-to-face counterparts. A more recent meta-analysis of over 1,000 studies on online learning published between 1996 and 2008 (U.S. Department of Education, 2009) also found that students in online learning courses performed better than those receiving face-to-face instruction. Most of these reviewed studies focused on college students and other adult learners, and educational delivery methods (synchronous vs. asynchronous) was not differentiated.

Likewise, Bernard et al. (2004) performed a meta-analysis of 232 empirical studies from 1985 to 2002 and reported a small yet statistically significant effect size favoring distance education in overall student achievement. However, Bernard's study divided student achievement outcomes based on the synchronicity of distance education 
delivery. In this study synchronous distance education consisted of courses delivered by videoconferencing, audioconferencing, or both. Bernard's findings suggest that students enrolled in these synchronous distance education modes did not perform as well as their classroom counterparts, while students enrolled in asynchronous distance education courses had higher levels of achievement compared to students in a classroom setting. Upon further analysis, Bernard et al. made suggestions for those implementing distance learning, including the need for active learning that includes collaboration between students, opportunities for communication including technologically mediated communication, and media that supports interactivity.

A meta-analysis of 14 studies comparing outcomes of K-12 distance education students was conducted by Cavanaugh et al. (2004). They reported no significant statistical difference in terms of academic achievement when comparing traditional instruction to distance education. Cavanaugh reported no factors had significant positive or negative effects when testing factors such as "grade level of the students, role of the distance learning program, role of the instructor, length of the program, type of school, frequency of the distance learning experience, pacing of instruction, timing of instruction... and the setting of the students" (p. 4). Cavanaugh's research team examined 14 studies published since 1999, representing 7,561 students. The small number of studies in this meta-analysis may indicate that high quality experimental research with complete data is difficult to come by in K-12 distance education. Although the authors concluded that distance education is as effective as a classroom environment, they also advise future research to understand why. As Cavanaugh et al. point out, "we need to know how to make it more effective, what factors contribute most to effectiveness, and in 
what contexts the factors operate" (p. 20). By comparing academic achievement and learning experience of students enrolled in completely asynchronous online independent study courses with online courses that are on a semester schedule with synchronous components, I hope to contribute to the knowledge base through this dissertation study.

While these meta-analyses produced important findings, none of them exclusively focused on online learning at the high school level. A study of the Virtual High School in Massachusetts, one of the most established virtual schools, indicates that students learn as much from their online courses as their counterparts do in face to face courses (Zucker \& Kozma, 2003).

Rather than focusing on student achievement and performance, other researchers studied student perceptions and their satisfaction with distance learning experiences. Noting that most distance learning studies were conducted on adult learners, Litke (1998) performed a relatively early study on Canadian virtual schooling at the middle school level. Students were interviewed over a two year period, while the researcher also collected other data such as diaries, grades, assignments, e-mail logs, and e-mail transcripts. Litke found that "student participants identified freedom, time flexibility, fewer distractions, better marks, more individual attention from teachers, a higher degree of satisfaction, and fewer hassles with teachers and other students" with online learning (p. 6). Deterrents, however, included a feeling of isolation, decreased contact with other students, and distractions such as computer games. Students noted online learning was not for everyone, and personal characteristics such as motivation, organization skills, and independence are important factors influencing academic success. 
In another Canadian study, Tunison and Noonan (2001) analyzed survey data from 50 secondary school students to examine their experience with online learning. While students indicated they were generally satisfied with their online learning experience and appreciated the autonomy and flexibility online learning allows them, they also indicated they often had difficulties managing their time effectively. Of relevance to my study, Tunison and Noonan also examined students' use of communication tools such as e-mail, bulletin boards, and chat rooms built into their online courses, and found that they did not use them much even though they recognized the value of these communication tools.

Examining issues of student satisfaction, the Southern Regional Education Board (SREB) had more than 2,000 middle and high school students complete a likert scale type questionnaire concerning their opinions on their 2007-2008 academic year online coursework (Thomas, 2008). Eighty percent of students felt they were academically prepared to take online courses, and that their coursework was designed and delivered well. Seventy-eight percent felt their instructor responded promptly to their questions and communicated well with them. Students again pointed out the importance of time management skills, with 55\% indicating they wished they had more time to spend on their coursework. A surprising result of this study is that although $80 \%$ of students felt prepared, only $68 \%$ of them stated they liked their online course, and an even lower $59 \%$ of students said they were willing to take another online course. No information was presented as to why these latter numbers are lower in comparison. My study examined student satisfaction with semester-based courses and asynchronous courses, focusing on 
how the timing of delivery, communication, and course completion schedule may be associated with both student satisfaction and academic achievement.

In summary, most research on distance learning to date has been performed on post-secondary students, and most research compares distance learning to traditional face to face instruction. Only a small number of studies focused on secondary school students, and few examined the effects of different delivery methods, such as synchronous vs. asynchronous, on student achievement or completion rates.

\section{Limitations of Prior Studies}

Although distance education studies at the high school level are increasing, much of the research done to date has been at the college level. Specifically, published studies relating online instruction and its outcomes have predominately focused on postsecondary education (Picciano \& Seaman, 2009). K-12 distance learning research was found to be scarce, and what is available consists mostly of anecdotal studies, personal opinions, and advice aimed for other practitioners wishing to implement distance learning strategies (Moore \& Thompson, 1990).

A particularly troubling aspect of increased implementation of K-12 distance education in recent years is that it has been implemented with a narrow and inadequate research base that draws from adult distance education studies and traditional face to face classroom learning environments (Rice, 2006). With most of the research done at the postsecondary level, it is inappropriate to generalize results to K-12 learners who learn differently from their adult counterparts (Barbour \& Reeves, 2009; Rice, 2006). 
Despite the growth of distance education research at all levels, few studies examined student learning experiences, effectiveness of instructional methods, and strengths and limitations of different methods of distance learning specifically (Nasseh, 1997). For example, there is little research comparing the effectiveness of alternative forms and methods of distance education delivery at the high school level (Pittman, 2003). As stated previously, most research to date compares online learning and other forms of distance education to traditional brick and mortar classrooms (Cavanaugh et al., 2009; Reeves, 2005; Rice, 2006; Schlosser, 1996). This creates other inherent difficulties when analyzing research results. Some researchers feel comparing different modes of instruction are inadequate because they do not account for the many complex variables resulting from different learning environments and the non-experimental nature of most distance learning research to date (LeBaron \& Tello, 1998; Saba, 2000). Considering the lack of K-12 research and research comparing different methods of distance learning, there is a definite need for current and relevant studies that address these aforementioned limitations.

\section{Theoretical Framework}

One of the advantages that distance and online learning affords is the individualized nature of students' learning experiences. Students can literally be a classroom of one. For that reason, the theoretical framework chosen for this research study is the American Psychological Association's (APA) Learner-Centered Principles. Instruction of any nature is an eclectic practice and of a multi-dimensional nature. The 
Learner-Centered Principles are a compilation of best practices from multiple conceptual frameworks, where the focus is on how an individual student creates the scaffolding for his or her learning experiences. Barbara McCombs, one of the original collaborators in the development of Learner-Centered Principles, and Donna Vakili provide an excellent and detailed list of instructional practices for building a community of distance learners utilizing the principles as a framework (McCombs \& Vakili, 2005). Citing previous research, their implications include the following suggestions for distance educators categorized into four factors for promoting learner-centered practice: cognitive and metacognitive factors; motivational and affective factors; developmental and social factors; and individual differences factors. These suggestions are selected for their relevance to aspects of this study, and are summarized in Table 1 below. 
Table 1. Learner-Centered Practice Implications for Distance Learning

Cognitive and

Metacognitive

Factors

- $\quad$ Provide ways to make unobservable learning (e.g. strategic thinking) available for reflection as well as online supports, allocations of time, and multiple passes through electronic conferences that can support metacognition and reflection on the learning process.

- Develop digital literacy and strategic thinking through searching, questioning, and discovering appropriate sources and uses of electronic information and a variety of resources.

- Actively involve students in discussing problems, participating in projects, and responding to activities.

- Support collaboration through the use of computer conferencing, chats, and other technology as a way for learners to construct knowledge, dialog and share with others, and contribute to a group.

Motivational and Affective Factors

- Do not assume online learners prefer less personal contact with instructors, are independent learners, are highly motivated to learn, are self-disciplined, and have high personal self-efficacy as these assumptions are not warranted for many students.

- Provide technical support such as needs assessment, prerequisites, 800 numbers, e-mail, peer networks, real-time chats, instant messaging and online tutorials.

- Use Socratic questioning to probe learning that occurs, as well as ongoing feedback and guided practice that helps learners become self-directed and motivated.

- Provide ways for students to assess and evaluate class discussions and share feedback with peers and instructors, thereby increasing motivation.

Developmental and Social Factors
- Structure opportunities for personal contact and develop online communication and social activities to foster a sense of community and assist students to feel less isolated.

- Provide ways for students to partner with teachers to teach them about technology, such as encouraging two-way communication and feedback relative to course expectations between students and teachers.

- Create hyperlinks to resources and discussions to aid in scaffolding learning and helping learners to reach the next level of development.

IndividualDifferences Factors
- Use strategies for individualizing learning such as nonlinear branching, multiple media, negotiated time schedules, and different learning structures.

- Use a variety of technologies such as multimedia and streaming technologies to appeal to different learning styles and meet the needs of students with disabilities.

- Provide ways for assignments to be graded electronically via a variety of assessments and have electronic feedback and grades available to students.

- Provide various levels of learner choice and control to match the needs, experience, and interest of different types of learners.

Note: Table 1 summarized from McCombs and Vakili, 2005 
McCombs and Vakili (2005) perspectives were chosen because of their applicability to this study comparing asynchronous independent study online courses with semester-based online courses with opportunities for students to interact with each other and their instructor in real time. Hence, communication tools in building a sense of community is especially a point of interest, as is scheduling and timing of course delivery. Training of distance educators in and implementation of Learner-Centered Principles may affect student perceptions and subsequent completion rates in courses offered at a distance. For example, studies have shown that timing and pacing of distance education courses combined with student motivation are contributing factors in distance education attrition rates (Hannum et al., 2008). Furthermore, a study done on training of facilitators of high school distance education students in rural schools found that those students whose local facilitators were trained in Learner-Centered Principles persisted in their distance education courses longer and had higher course completions rates (Hannum et al.).

\section{Connecting Theoretical Framework to Students' Online Learning Experiences}

With this study, I hope to look beyond the simplified explanation of distance education in the past that merely compared distance education to traditional classrooms without looking at the instructional design aspects of distance education formats. When looking at design, the Learner-Centered Principles can be applied to the individualized nature of online learning. 
In fact, the Learner-Centered Principles were used in this study to examine student experiences as outlined in my first research question that asked "how do learning experiences of high school students in semester-based courses differ from those in asynchronous courses". As explained in greater detail in Chapter Three on "Methodology", I constructed an online student survey to administer to students enrolled in both asynchronous and semester-based courses. Each question of the survey was grouped into various categories including student's background information, satisfaction levels with various aspects of online coursework, or one of the four categories of Learner-Centered Principles (cognitive and metacognitive, motivational and affective, developmental and social, and individual differences).

The research of McCombs and Vakili (2005) on a learner-centered framework for online learning was used to guide this study on grouping questions from my survey into appropriate categories of Learner-Centered Principles. A summary variable that calculated the means of all the individual survey questions for each of the four principles was also constructed. Appendix C (p. 100) details the survey questions used in this study, the organization of questions into categories, and the creation of summary variables.

\section{Current Study and Significance}

As for the application of this study, the results can be used to see if the "no significant difference phenomenon" holds true for MU High School students. Thomas L. Russell's book, The No Significant Difference Phenomenon, is a "research bibliography of 355 research reports, summaries and papers that document no significant differences in 
student outcomes between alternate modes of education delivery" (WCET, 2008, retrieved October 13). This is a very significant publication in the field of distance learning, and one which many later studies use for comparison and benchmarking purposes. Russell's work is an example of what Galvan calls a "landmark" study that establishes "historical importance in developing an understanding of a topic or problem" (p. 27)

Also, this study will help to bridge the gap of prior distance education research. As already evidenced in this literature review, many distance education studies were done with college and adult learners rather than younger students. Those studies that have been done on K-12 students have primarily compared distance learning methods to traditional classroom instruction. This study, on the other hand, compares different methods and scheduling of distance education course delivery using high school aged participants.

At the institutional level of my personal workplace, the findings from my study will inform decision making regarding what students want and need in coursework. Additionally, the study will help guide how my institution allocates resources such as personnel, time, technology, and money during the course development process. Consequently, the study will be useful for efficient use of our resources, which is especially important given the current economic climate in the United States.

At the individual student level, results may be used to help identify learning preferences of students. A possible way to further extend the study is the development of an instrument designed to predict which mode of course delivery is a good match for individual students. This extension may be especially promising with the construction of a carefully designed survey as a means to collect critical data from students. 
Furthermore, citing criticisms of previous studies, some distance learning scholars recommend that studies be directed to examination of characteristics of effective K-12 distance education programs including instructional methods and practices (Black et al., 2009; Cavanaugh et al., 2009; Rice, 2006; Roblyer \& Marshall, 2003; Thomas, 2008). As a principal of a distance education high school located on a land-grant university campus, I examined the effectiveness of online courses for improving student performance at my school, the University of Missouri High School, or MU High School. I wanted to know if students were being adequately served and their educational needs were being met online. Specifically, I wished to know if the timing of online course delivery (completely asynchronous versus semester-based courses with synchronous course components) influences satisfaction and academic achievement of high school students.

Therefore, for this quantitative study, I am posing three research questions relating to online courses students take through MU High:

Research Question 1: How do learning experiences of high school students in semester-based courses differ from those of students in asynchronous courses?

Research Question 2: Are students in semester-based online courses more satisfied with their course experience than the students in asynchronous online courses?

Research Question 3: Do students in semester-based online courses perform better and have a higher completion rate than students enrolled in asynchronous online courses, controlling for previous online course experience and student gender? 
The following hypotheses were tested in this study:

H1: The students in semester-based online courses have more positive learning experiences than the students in asynchronous online courses.

H2: The students in semester-based online courses will be more satisfied with their course experience than the students in asynchronous online courses.

H3: The students in semester-based online courses achieve higher and have a higher completion rate than the students in asynchronous online courses. 


\section{CHAPTER 3: METHODOLOGY}

\section{Introduction}

Online education is currently growing at a phenomenal rate with little experimental and quasi-experimental research having been completed at the high school level. Leaders of online high schools need research-based data to base decisions on which factors may, or may not, enhance student learning experiences and outcomes. With the increasing popularity of online courses, I sought to know if students are being adequately served and their educational needs are being met in an online learning environment. For example, I wanted to compare the learning experiences, satisfaction levels, academic achievement, and course completion rates for students in online asynchronous courses to their counterparts in semester-based online courses.

\section{Research Design}

Since students self-select which type of course they enroll in rather than being randomly selected to enroll in courses, my methodology was a quasi-experimental research design (Creswell, 2003). Data was collected to either support or refute the theory that online and semester-based learning has causal effects on such outcomes as student achievement (Creswell, pp. 7-8). Student data such as enrollment records, final course grades, and withdrawal rates were collected from my school's student information system (SIS) database. Additionally, I conducted an online student survey. A survey was used as 
an instrument "to collect information from or about people to describe, compare, or explain their knowledge, feelings, values, and behavior" and was self-administered to students (Fink, 2006, p. 1). The survey asked students specific questions on such matters as their online learning experiences and their satisfaction with these experiences.

\section{Participants and Sample Selection}

Participants in this study were students who voluntarily enrolled and completed online courses at MU High School during the fall 2009 and spring 2010 semesters (the 2009-2010 academic year), and the fall 2010 semester. Students were divided into two groups for this study. One group of students consisted of those who completed asynchronous online independent study high school courses. The other group consisted of those students who have completed semester-based online courses that include a schedule, due dates for assignments, discussion forums, and scheduled chat time with the instructor and other classmates. Since MU High School is a distance learning institution, students were from various locations and at different stages of their education. The only common dominator is the fact that they chose to enroll in online courses through MU High School. For this study, a potential pool of 53 unique student participants enrolled in and completed semester-based courses for the 2009-2010 academic year and the fall 2010 semester. Enrollments in the asynchronous versions of the corresponding semester-based course titles totaled 1,149 unique student participants for the same time period. An attempt was made to match the 53 semester-based students with 53 asynchronous students in corresponding course titles by randomly selecting asynchronous students by 
course title. This matching method made sure that students in the semester-based and asynchronous courses were enrolled in the same courses. However, the response rates between the two groups of students were not the same. There was a low response rate overall, but especially so for asynchronous students. Even for those students that did return surveys, the responses were not equivalent by course title for the two groups. Consequently, to ensure a large enough sample size, the pool of asynchronous students invited to participate in the online survey was expanded to 160 students, also chosen by course title, along with the 53 students in semester-based courses.

Because many of these students were minors, the University of Missouri's Institutional Review Board (IRB) required an extra step before the study began to help protect the interests of those students under the age of 18 . Not only were minor students sent an informed consent letter prior to the study, but their parents were also sent an informed consent letter and a parental consent form. Details of the study and the minimal risks involved were described to both parents and students. Parents of minors were required to sign and return a parental consent form before minors were sent an email with access information and directions for the survey. Students over the age of 18 were only sent an informed consent letter prior to the survey email. Informed consent letters, the parental consent form, and the survey email with directions for accessing the survey and completing it are located in Appendix B.

Data was collected from MU High's SIS database to identify students who enrolled in semester-based courses and asynchronous independent study in matching course titles. Information collected from MU High School's SIS included course completion rates, final course grades, and student gender. Screenshots of a dummy 
student record are included in Appendix A demonstrating the types of information the SIS collects.

\section{Data Collection and Instrumentation}

To solicit as many student responses as possible, three follow-up email messages were sent reminding students to please complete the survey. Because of the extremely small number of semester-based students who replied, phone calls were also made in an attempt to gather additional information for that group of students. Thirty-seven students in asynchronous courses responded to the survey out of 160 invited potential participants. Thirteen responses were received from the 53 unique students enrolled in semester-based courses during the 2009-2010 school year and the fall semester of 2010. Consequently, 50 student responses in total were received with a response rate of $23 \%$. The survey responses were analyzed using SPSS 19.0. While the response rate to the 11-question online survey with 37 separate item stems for student responses was lower than hoped, there was sufficiently variability and reliability in student responses in all but one item. This single item was discarded in further data analyses.

An online survey was constructed and sent to students in both the selected asynchronous and semester-based courses to assess student experiences after their course completion. Incentives to increase student response rates were \$5.00 Amazon gift cards to all students returning a survey, and an opportunity to win another gift card in the amount of $\$ 75, \$ 50$, or $\$ 25$ with winners chosen randomly from all responses received. The survey asked students about their previous experience with online courses, their 
comfort level with taking online courses, how satisfied they were with different aspects of their online course experience, and also their parents' level of educational attainment. Questions on the survey were designed around the four main factors of my conceptual framework, the American Psychological Association's Learner-Centered Principles. Thus, questions for each of the four factors - cognitive and metacognitive, motivational and affective, developmental and social, and individual differences - were included in the survey (APA, 1997). A complete survey instrument is included within Appendix B.

Because postal addresses had been collected in the SIS, information regarding the survey and its importance were sent by mail along with parental consent forms (for those students under the age of 18) and informed consent letters. Information on how to access and complete the survey was sent to students by email approximately two weeks later. Sample consent letters, recruiting email, and directions for completing the survey are also located in Appendix B. The survey was administered online during spring of 2011.

\section{Variables}

\section{Online Course Delivery Method}

The online course delivery mode was identified using the MU High's SIS. Semester-based courses were coded as 1 and asynchronous courses as 0 .

\section{Student Achievement}

Students' end-of-course grades were used as a proxy of student achievement. The grade ranges from A to Withdraw, and the letter grades were coded numerically as $\mathrm{W}=0$, $\mathrm{F}=1, \mathrm{D}=2, \mathrm{C}=3, \mathrm{~B}=4$, and $\mathrm{A}=5$. 


\section{Completion Rates}

Students who completed their online coursework were coded as 1 and students who did not complete the course or withdrew from their course were coded as 0 .

\section{Students' Online Learning Experiences}

As briefly discussed in Chapter Two, students' learning experiences were measured by survey questions that were grouped into one of the four categories of Learner-Centered Principles using McCombs and Vakili’s (2005) guidelines. Student responses to each survey question were coded as $1=$ Strongly agree or not applicable, $2=$ Agree, $3=$ Neutral, $4=$ Disagree, and $5=$ Strongly disagree. A summary variable of each Learner-Centered Principle factor (cognitive and metacognitive, motivational and affective, developmental and social, and individual differences) was created by taking the mean of the individual questions comprising each respective category. Appendix $\mathrm{C}$ (p. 100), the online course survey and SIS data codebook for this study, contains details on the grouping of questions into Learner-Centered Principle factors and the creation of corresponding summary variables.

\section{Student Satisfaction}

Student satisfaction levels were measured using an online survey with 7 items. The students were asked, "How satisfied are you with the following aspects of this course?" with the following items: 1) instructor, 2) course structure, 3) course content, 4) assessments and grading, 5) course materials, 6) communication with my classmates, and 7) overall quality. Their responses were coded into $1=$ Not satisfied at all, $2=$ Not satisfied, $3=$ Neither, $4=$ Satisfied, and 5=Very satisfied. A summary variable of student satisfaction was created by taking the mean of these 7 items. 


\section{Parents' Education Level}

Parents' education level was measured using an online survey with 2 items. The students were asked, "What level of education has your mother completed?" and "What level of education has your father completed?". Possible responses were coded into 1=Some high school, 2=High school graduate, 3=Some college, 4=Bachelor's degree, $5=$ Some graduate level work, $6=$ Graduate degree, and $7=$ Not sure. The mean of each student's two parents was computed and used in the data analysis.

\section{Previous Online Course Experience}

Previous online course experience was measured using an online survey with 2 items. The students were asked, "Prior to taking this course, how many online courses have you taken?". Their responses were coded corresponding to the number they have indicated: $0,1,2,3,4$, and 5 or more.

\section{Student Comfort Level with Online Coursework}

The students were asked, "How comfortable were you with the idea of taking online courses before taking this one?". Their responses were coded into 1=Very uncomfortable, 2= Uncomfortable, 3=Somewhat uncomfortable, 4=Somewhat comfortable, $5=$ Comfortable, and $6=$ Very comfortable.

\section{Prior Number of MUHS Online Courses (from SIS)}

The total number of online courses students had taken from MU High School was obtained from the SIS. The numbers ranged from 0 to 40 .

\section{Student Gender}

Gender information was obtained from the SIS. Male students were coded as 0, while female students were coded as 1 . 


\section{Data Analysis}

All the data were analyzed using SPSS 19.0. For the first research question, "how do learning experiences of high school students in semester-based courses differ from those of students in asynchronous courses", the means of each survey question were computed for both groups of students (semester-based vs. asynchronous) replying to the survey, and an independent means t-test was conducted to examine if the means of students' learning experiences between these two groups were statistically different or not. The p-value of less than 0.05 would indicate "the means of the two groups are significantly different" (Field, 2005, p. 303).

For the second research question that asks "are students in semester-based online courses more satisfied with their course experience than the students in asynchronous online courses", student survey responses were also used to compare asynchronous with semester-based students. A multiple regression analysis was conducted to examine the relationship between course type and each of seven measures of course satisfaction (instructor, course structure, content, assessments, materials, communication, and course quality), controlling for parents' education level, prior online course experience, and comfort level with online courses.

To answer research question 3, "do students in semester-based online courses perform better and have a higher completion rate than students enrolled in asynchronous online courses, controlling for previous online course experience and student gender", rather than using the responses received from the 50 students who completed the survey, I used data on grades and completion rates from a much larger pool of all students who 
enrolled in semester-based courses during the time period examined and their equivalent enrollees in asynchronous titles. During the academic year of 2009-2010 and the fall of 2010, there were 93 individual course enrollments for semester-based courses and 1,597 course enrollments in equivalent asynchronous courses. For the data analysis, this enrollment data from the SIS was aggregated to individual level. The results of the SPSS aggregation yielded 58 semester-based and 1,149 asynchronous cases on which to perform further data analysis. Note that the 58 students obtained from the SIS were enrollees in semester-based courses, but did not necessarily complete their coursework. Hence, this explains the discrepancy with only 53 students completing their coursework and earning letter grades, and subsequently invited to participate in the survey portion of this study.

A t-test was performed to compare mean grades of the two groups and a chisquare test was conducted to compare the percentage of students who completed their courses. Multiple regression analysis was conducted with the dependent variable of student grades, independent variable of online course delivery method (asynchronous or semester-based), and control variables of parents' education level, and previous online course experience. Logistic regression analysis was conducted with the dependent variable of completion rate $(1=$ completed, $0=$ did not complete $)$ with the same independent and control variables as the multiple regression. 


\section{Reliability, Validity, and Pilot Testing}

The reliability of a study is indicated by the consistency of its results, while validity refers to the accuracy of the information obtained from a study (Fink, 2006). Ideally, using a proven and already validated survey, along with pilot testing, would increase a study's reliability and validity. Because of the specificity of my study's topic, however, there is not a previously tested and validated survey I am aware of that asks exactly the types of questions I wish to ask of students. Therefore, I developed my own survey and used the following strategies to improve its reliability and validity.

To assist with the reliability and validity of my study, a pilot test of the initially constructed student survey was conducted during the late summer and fall of 2010. An invitation to participate in the survey was sent to 142 randomly selected students and 13 students provided responses. Responses to each survey item were examined to check for variability. Every survey item had received at least three different responses from students. This is an indication that all survey items showed sufficient variation and distribution for statistical analysis.

Fink (2006) states that "another measure of reliability is how internally consistent the questions on a survey are in measuring the characteristics, attitudes, or qualities they are supposed to measure" (p. 38). Because my theoretical framework consists of the Learner-Centered Principles, I grouped the majority of my survey items into one of the four Learner-Centered Principle categories based on which category best correlates with each individual item. Using SPSS, a Cronbach's alpha was computed to test the reliability of each item measuring the four categories of the Learner-Centered Principles 
and also student satisfaction (Field, 2005). The alpha values for the Learner-Centered Principles summary variables were 0.64 for cognitive and metacognitive factors, 0.89 for motivational and affective factors, 0.69 for developmental and social factors, and 0.90 for individual differences factors. The satisfaction summary variable representing seven areas of students' satisfaction with their courses (instructor, structure, content, assessments, materials, communication with classmates, and overall quality) had an alpha value of 0.90 .

\section{Summary}

In summary, I presented an overview of a quasi-experimental study to assess student experiences, satisfaction levels, academic achievement, and completion rates in online asynchronous and semester-based courses. The quantitative research design for this study was outlined, including how participants were selected, the collection of information, and the variables used in data analysis and their coding. A brief description of how data was analyzed in attempts to answer each question was also included, along with an overview of how the study's survey was pilot tested to assure sufficient variability in responses, reliability and validity. 


\section{CHAPTER 4: RESULTS}

\section{Introduction}

This study examined high school students' experiences and academic performance in asynchronous and semester-based online courses.

An online survey collected student background information including parents' education levels, comfort level with online coursework, and prior experience with online coursework, as well as student experiences with their online course categorized into four factors based on the theoretical framework of the APA's Learner-Centered Principles: cognitive and metacognitive factors, motivational and affective factors, developmental and social factors, and individual differences factors. Student satisfaction measures with their online courses were also included. Combined summary variables composed of each of the four Learner-Centered Principles factors as well as a satisfaction summary variable were included in the data analyses. Information on student grades and completion rates for all students enrolled in semester-based courses during the 2009-2010 academic year and the fall of 2010 was obtained from MU High School's SIS, as was data on grades and completion rates for all students during the same time period enrolled in the equivalent asynchronous course titles.

\section{Descriptive Statistics}

Table 2 below presents the descriptive statistics of all the variables analyzed in this study, reporting the mean, standard deviation, and minimum and maximum values. The table presents both the survey data collected from 50 students and MU High SIS data 
from 1,207 students. It lists descriptive statistics for each survey item, and also includes summary variables for each of the four Learner-Centered Principles factors and satisfaction with online coursework. All survey items and the coding scheme for each item can be found in Appendices B and C, respectively.

Table 2

Descriptive Statistics: Student Survey Responses and Characteristics

\begin{tabular}{|c|c|c|c|c|c|c|}
\hline \multirow{3}{*}{$\begin{array}{l}\text { Student } \\
\text { Background } \\
\text { (from } \\
\text { Survey) }\end{array}$} & \multirow{6}{*}{$\begin{array}{l}\text { Prior online courses } \\
\text { Comfort level with online courses } \\
\text { Parents' educational level (mean } \\
\text { of mother \& father) }\end{array}$} & \multirow[t]{2}{*}{$\mathrm{N}$} & \multirow[t]{2}{*}{ Mean } & \multirow[t]{2}{*}{ SD } & \multirow[t]{2}{*}{ Min. } & \multirow[t]{2}{*}{ Max. } \\
\hline & & & & & & \\
\hline & & & & & & \\
\hline & & 50 & 2.86 & 2.29 & 1 & 6 \\
\hline & & 50 & 4.14 & 1.47 & 1 & 6 \\
\hline & & 50 & 3.93 & 1.46 & 1 & 6 \\
\hline Student & Gender & 1,207 & 0.52 & 0.50 & 0 & 1 \\
\hline $\begin{array}{l}\text { Background } \\
\text { (from SIS) }\end{array}$ & $\begin{array}{l}\text { Number of prior MUHS online } \\
\text { courses }\end{array}$ & 1,207 & 5.20 & 5.69 & 0 & 40 \\
\hline Student & Student grades & 1,207 & 2.25 & 1.96 & 0 & 5 \\
\hline $\begin{array}{l}\text { Outcomes } \\
\text { (from SIS) }\end{array}$ & Completion rates & 1,207 & 0.64 & 0.48 & 0 & 1 \\
\hline \multicolumn{7}{|l|}{ Online } \\
\hline \multicolumn{7}{|l|}{ Course } \\
\hline \multicolumn{7}{|l|}{ Experiences } \\
\hline 1. Cognitive & Participated in online discussions & 50 & 1.96 & 1.48 & 1 & 5 \\
\hline $\begin{array}{l}\& \text { Meta- } \\
\text { cognitive }\end{array}$ & $\begin{array}{l}\text { Class project was part of } \\
\text { coursework }\end{array}$ & 50 & 2.42 & 1.57 & 1 & 5 \\
\hline \multirow[t]{3}{*}{ Factors } & $\begin{array}{l}\text { Could ask questions of instructor } \\
\text { easily }\end{array}$ & 50 & 2.26 & 1.12 & 1 & 5 \\
\hline & $\begin{array}{l}\text { Communicated \& shared opinions } \\
\text { with instructor }\end{array}$ & 50 & 2.52 & 1.40 & 1 & 5 \\
\hline & $\begin{array}{l}\text { Cognitive Summary (mean of } 4 \\
\text { variables above) }\end{array}$ & 50 & 2.27 & 0.82 & 1 & 4.2 \\
\hline 2.Motivation- & Received tech support & 50 & 2.00 & 0.93 & 1 & 4 \\
\hline $\begin{array}{l}\text { al \& Affective } \\
\text { Factors }\end{array}$ & $\begin{array}{l}\text { Instructor's guidance helped me } \\
\text { complete course }\end{array}$ & 50 & 2.14 & 1.03 & 1 & 5 \\
\hline
\end{tabular}




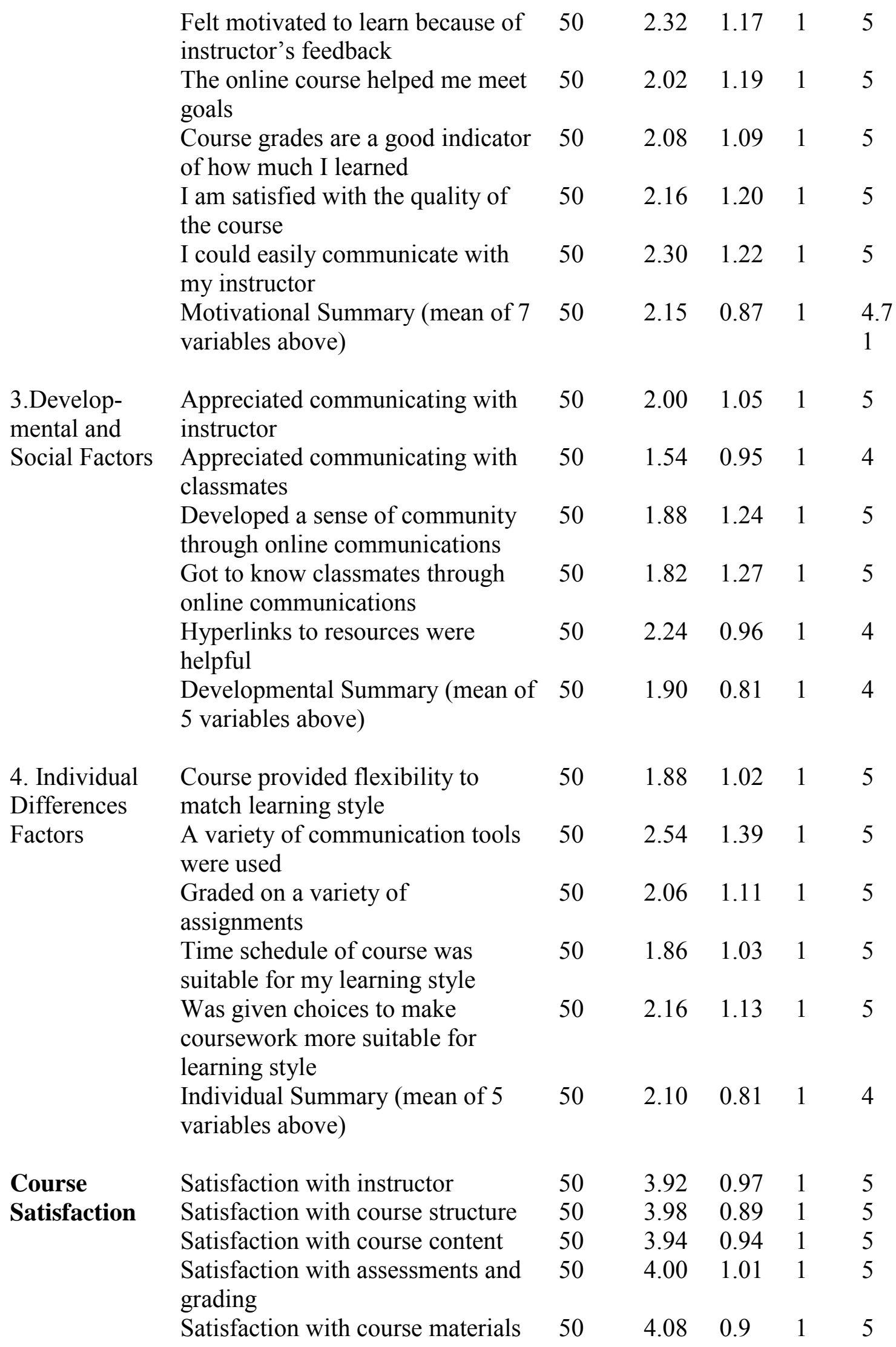




\begin{tabular}{lccccc}
$\begin{array}{l}\text { Satisfaction with classmate } \\
\text { communications }\end{array}$ & 50 & 3.08 & 1.09 & 1 & 5 \\
$\begin{array}{l}\text { Satisfaction with overall quality of } \\
\text { course }\end{array}$ & 50 & 4.08 & 1.05 & 1 & 5 \\
$\begin{array}{l}\text { Satisfaction Summary (mean of 7 } \\
\text { variables above) }\end{array}$ & 50 & 3.87 & 0.77 & 1 & 5 \\
$\begin{array}{l}\text { Grade student would give MUHS } \\
\text { 5rive }\end{array}$ & 4.26 & 1.00 & 2 & 5 \\
\hline
\end{tabular}

For student background, the 50 students who completed the survey were asked how many online courses they had taken prior to the course they were being surveyed about. This variable is identified as prior online courses above, and student answers ranged from 0 (coded as 1 ) to 5 or more (coded as 6). Students also ranked their comfort level with taking online courses. They generally ranked their comfort at a very high level, with a mean score of 4.14 on a scale ranging from 1 to 6 . Since the students were all enrolled in online courses, it is reasonable to expect them to be comfortable with an online mode of course delivery. Students reported their parents' educational level. The mean of combining both the mother and father scores was calculated at 3.93, which translates to being between some college at level 3 and very close to level 4 of having a bachelor's degree.

Background information from 1,207 students who enrolled in semester-based courses and their student counterparts in asynchronous courses during the specified timeframe was also obtained from MU High School's SIS. This student background information from the SIS included gender (coded as 0 for male, and 1 for female), and the number of prior online courses students had taken through MU High School. Prior MU High courses had a range of 0 to 40 , with a mean of 5.20 courses. Student outcomes, namely the course grades students earned and student completion rates, were also 
obtained from the SIS. The mean grade earned was 2.25 , with an " $\mathrm{A}$ " being coded as 5 , an "F" as 1 , and "W" (or withdrawal/noncompletion) as 0 . Student completion rate overall was 0.65 , with noncompletions being coded as 0 , and course completions being coded as 1 .

Using the survey responses to compare the four online course experience summary variables that correspond to the Learner-Centered Principles factors, the summary variable that students ranked the highest was that of cognitive and metacognitive, with a mean of 2.27. Conversely, students scored the developmental and social summary variable lowest with a mean of 1.90. Likewise, the individual variables within that group were generally low, with the only variable of "hyperlinks to resources were helpful" scoring above a 2 with a mean of 2.24 .

As indicated in Table 2, students generally rated their satisfaction levels positively. In fact, the satisfaction summary variable, an average of seven different measures of satisfaction, had the highest summary variable mean with a score of 3.87 on a scale ranging from 1 (not satisfied at all) to 5 (very satisfied). The individual satisfaction variables students ranked highest include satisfaction with their course materials and overall quality of their online course, both with a mean of 4.08 . Additionally, if students were given the option of assigning a grade to MU High, the mean grade they would give is 4.26 with an " $A$ " being coded as 5 , and an " $F$ " as 1 . The lowest scoring individual satisfaction variable was that of satisfaction with classmate communications, with a mean of 3.08 . 
This overview of the study's descriptive statistics sets the stage for a more thorough examination of the data. The next few sections present the findings of statistical tests to address the study's three research questions.

\section{Student Course Experiences by Course Type}

To address the first research question of "how do learning experiences of high school students in semester-based courses differ from those of students in asynchronous courses", t-tests were conducted. An independent means t-test compares the means of two different groups of subjects (Field, 2005). In this study, the two groups are based on course delivery method - those students who took asynchronous courses and those who took semester-based courses. T-values were computed for each of the four factors related to online course experiences: cognitive and metacognitive, motivational and affective, developmental and social, and individual differences. In addition, the mean values for the final course grade earned by students, completion rates, course satisfaction, parents'

education level, prior experience with online coursework, and comfort level with online coursework were compared between students enrolled in asynchronous and semesterbased courses. Table 3 displays means and standard deviations of these variables by course delivery method (asynchronous vs. semester-based), along with t-values for the mean differences and chi-square values for percentage differences. 
Table 3

Student Survey Responses and Characteristics by Course Delivery Method

\begin{tabular}{|c|c|c|c|c|c|}
\hline & & $\mathrm{N}$ & $\begin{array}{l}\text { Mean/ } \\
\text { Percentage }\end{array}$ & SD & $\begin{array}{l}\text { t-value/ } \\
X^{2} \text { value }\end{array}$ \\
\hline \multicolumn{6}{|l|}{$\begin{array}{l}\text { Student } \\
\text { Experiences } \\
\text { with Online } \\
\text { Courses }\end{array}$} \\
\hline \multirow{2}{*}{$\begin{array}{l}\text { 1. Cognitive \& } \\
\text { metacognitive }\end{array}$} & Asynchronous & 37 & 2.34 & 0.84 & $\mathrm{t}=.75$ \\
\hline & Semester & 13 & 2.07 & 0.78 & \\
\hline \multirow{2}{*}{$\begin{array}{l}\text { 2. Motivational } \\
\& \text { affective }\end{array}$} & Asynchronous & 37 & 2.14 & 0.91 & $\mathrm{t}=-0.09$ \\
\hline & Semester & 13 & 2.16 & 0.78 & \\
\hline \multirow{2}{*}{$\begin{array}{l}\text { 3.Developmental } \\
\text { \& social }\end{array}$} & Asynchronous & 37 & 1.82 & 0.77 & $\mathrm{t}=-1.17$ \\
\hline & Semester & 13 & 2.12 & 0.91 & \\
\hline \multirow{2}{*}{$\begin{array}{l}\text { 4.Individual } \\
\text { differences }\end{array}$} & Asynchronous & 37 & 2.19 & 0.79 & $\mathrm{t}=1.32$ \\
\hline & Semester & 13 & 1.85 & 0.84 & \\
\hline \multirow{2}{*}{$\begin{array}{l}\text { Course } \\
\text { Satisfaction }\end{array}$} & Asynchronous & 37 & 3.88 & 0.72 & $\mathrm{t}=0.18$ \\
\hline & Semester & 13 & 3.84 & 0.94 & \\
\hline \multirow{2}{*}{$\begin{array}{l}\text { Course Grade } \\
\text { Student Earned } \\
\text { (from SIS) }\end{array}$} & Asynchronous & 1,149 & 2.21 & 1.96 & $\mathrm{t}=-2.70 * *$ \\
\hline & Semester & 58 & 2.92 & 1.67 & \\
\hline $\begin{array}{l}\text { Completion } \\
\text { Rates (from }\end{array}$ & Asynchronous & 1,149 & $62.4 \%$ & & $\mathrm{X}^{2}=13.51 * * *$ \\
\hline SIS) & Semester & 58 & $86.2 \%$ & & \\
\hline \multicolumn{6}{|l|}{$\begin{array}{l}\text { Student } \\
\text { Background } \\
\text { (from survey) }\end{array}$} \\
\hline \multirow{2}{*}{$\begin{array}{l}\text { Parents } \\
\text { education }\end{array}$} & Asynchronous & 37 & 3.99 & 1.44 & $\mathrm{t}=0.46$ \\
\hline & Semester & 13 & 3.77 & 1.55 & \\
\hline
\end{tabular}




\begin{tabular}{|c|c|c|c|c|c|}
\hline Prior online & Asynchronous & 37 & 2.81 & 2.25 & $\mathrm{t}=-0.25$ \\
\hline & Semester & 13 & 3 & 2.48 & \\
\hline Comfort level & Asynchronous & 37 & 4.11 & 1.49 & $\mathrm{t}=-0.26$ \\
\hline coursework & Semester & 13 & 4.23 & 1.48 & \\
\hline $\begin{array}{l}\text { Student } \\
\text { Background } \\
\text { (from SIS) }\end{array}$ & & & & & \\
\hline Gender & Asynchronous & 1,149 & $\begin{array}{l}48.2 \% \text { male } \\
51.8 \%\end{array}$ & & $X^{2}=0.25$ \\
\hline & Semester & 58 & $\begin{array}{l}\text { female } \\
44.8 \% \text { male } \\
55.2 \% \\
\text { female }\end{array}$ & & \\
\hline $\begin{array}{l}\text { Number of prior } \\
\text { MUHS online }\end{array}$ & Asynchronous & 1,149 & 5.11 & 5.46 & $\mathrm{t}=-2.50 * *$ \\
\hline courses & Semester & 58 & 7.02 & 8.85 & \\
\hline
\end{tabular}

To be considered statistically significant, a t-test value should be equal to or greater than 1.96. As is apparent in Table 3 above, none of the summary variables from the survey (the four categories of student experiences and course satisfaction) display a statistically significant difference between the two groups of students. The largest t-value of all survey variables displayed in Table 3 was the summary variable for individual differences factors with a t-value of 1.32. The second highest absolute t-value of -1.17 occurred with the developmental and social factors summary variable which emphasizes communication between students and fellow classmates. Given the inherent differences of how the asynchronous and semester-based courses are delivered, it is surprising that there is not a larger and statistically significant difference between the two groups of 
students for both of the aforementioned summary variables. Conversely, the lowest tvalues between the two groups of students were the summary variables of motivational and affective factors, and course satisfaction, with t-values of -0.09 and 0.18 , respectively. The lack of statistical significance between asynchronous and semesterbased students as reported in student surveys for all student experiences and course satisfaction variables does not support my first hypothesis.

Results of the SIS data analysis, however, are markedly different from the information gathered from student surveys. From the SIS, the mean letter grade of semester-based students was found to be 2.92 , while the asynchronous student mean was markedly lower at 2.21. Because the absolute t-value comparing means of the two groups is -2.70 and greater than 1.96 , the difference in course grades is statistically significant. Likewise, completion rates from the SIS were found to be at $62.4 \%$ for asynchronous students, and $86.2 \%$ for semester-based students. The resulting chi-square value of 13.51 shows a very significant difference with $\mathrm{p}<0.001$, as indicated in Table 3 .

Student background information was gathered from both the survey and MU High's SIS. Based on survey results, there was no significant difference between asynchronous and semester-based students in terms of their parents' education level, prior online coursework, and comfort level with online coursework with t-values of 0.46 , 0.25 , and -0.26 , respectively. SIS gender data showed no statistical difference, with a chisquare value of 0.25 , although there were slightly more females than males in both groups of students and a larger difference in numbers with semester-based courses. Semester-based students had taken more online courses through MU High School with a 
mean of 7.02 as compared to asynchronous students with a mean of 5.11. This information from the SIS had a $\mathrm{p}<0.01$.

\section{Relationship between Course Delivery Method and Student Satisfaction}

The second research question, "are students in semester-based online courses more satisfied with their course experience than the students in asynchronous online courses" was tested using multiple regression.

\section{Multiple Regression}

To determine whether or not the course delivery method (asynchronous v. semester-based) is associated with student satisfaction in online courses, multiple regression analysis using survey results was performed. Multiple regression is a method of predicting an outcome from independent variables, and is expressed as $\mathrm{R}^{2}$, or the percentage of the variation in the outcome explained by the independent variables (Field, 2005). In this study, the dependent variables were seven measures of how satisfied students were with aspects of their online coursework. Results of these multiple regression analyses are displayed in the following Table 4 which summarizes the relationship between course delivery method and each of seven measures of course satisfaction (instructor, course structure, content, assessments, materials, communication, and course quality), controlling for three variables for student background information: parents' education level, prior online course experience, and student comfort level with taking online coursework. 


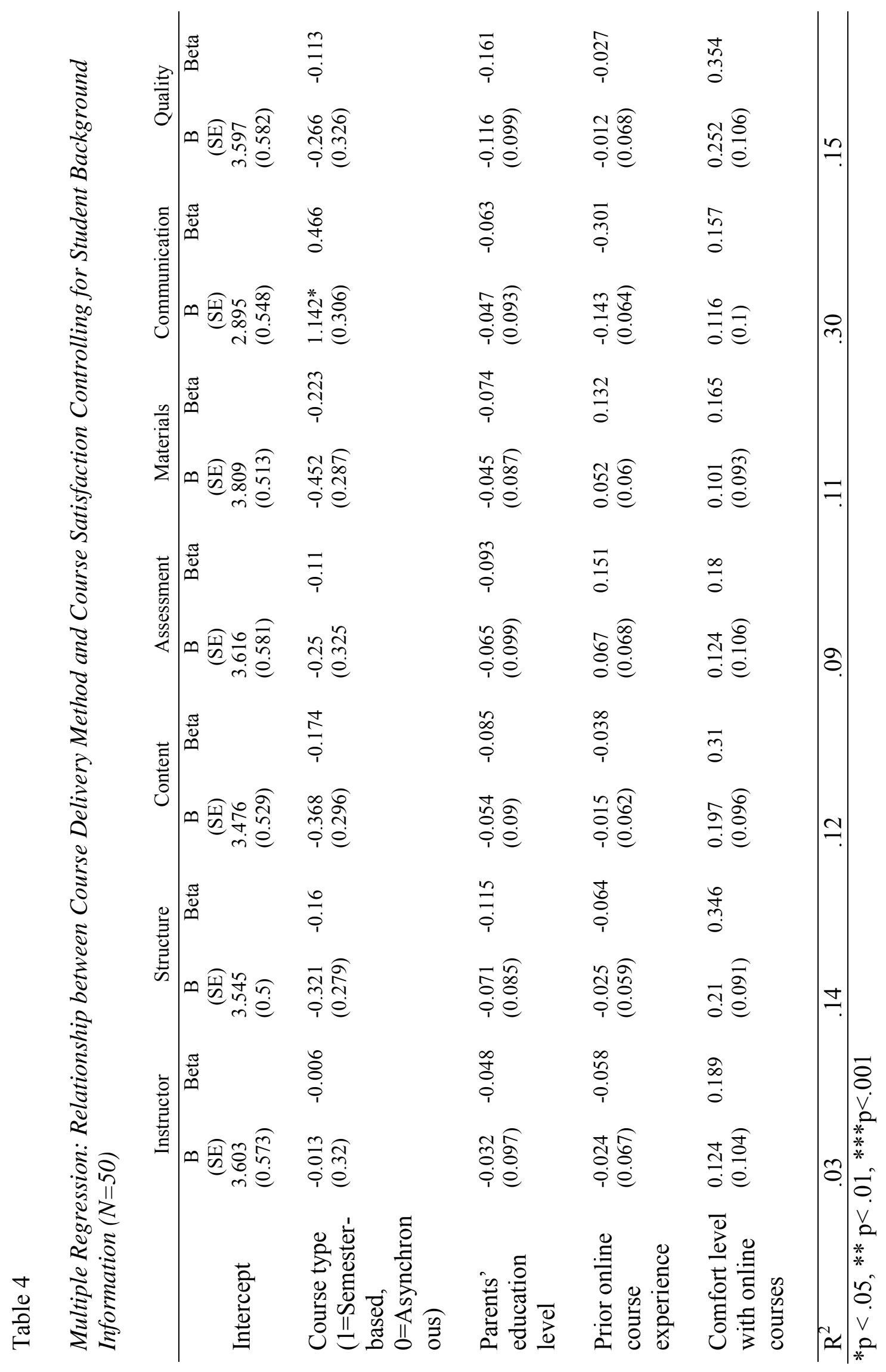


The only significant difference by course delivery method in any of the seven measures of student satisfaction was for communication with classmates as indicated by the asterisk in Table 4's multiple regression analysis. This result, however, is not surprising and should be expected given the fact that there is no communication between classmates in the asynchronous courses, while students in semester-based courses are required to have regular communication through online chats or threaded discussion boards as part of their coursework.

It is surprising that there was no statistical significance for any of the other six measures of student satisfaction (instructor, structure, content, assessments, materials, or quality) in regards to students' online learning experience, as reported by students in their survey responses. If nothing else, it might be expected that because of increased communication, students in semester-based courses may be more satisfied with their instructor and structure of their coursework. This overarching lack of statistical significance with respect to student satisfaction does not support my second hypothesis.

\section{Relationship between Course Delivery Method and Student Achievement}

To address research question three, "do students in semester-based online courses perform better and have a higher completion rate than students enrolled in asynchronous online courses, controlling for previous online course experience and student gender?", multiple regression and multiple logistic regression analyses were conducted using SPSS 19.0 and data from MU High's SIS. The final course grades students earned were examined as the dependent variable in a multiple regression analysis, and the completion 
rates $(1=$ completed, $0=$ not completed $)$ were examined as the dependent variable in a multiple logistic regression.

\section{Course Delivery Method and Student Grades}

For the multiple regression analysis summarized in Table 5 below, gender and previous online course experience were analyzed as the control variables in examining the relationship between course delivery method and student grades.

Table 5

Multiple Regression: Relationship between Course Delivery Method and Student Grades Controlling for Student Background Information $(N=1,207)$

\begin{tabular}{|c|c|c|c|c|c|}
\hline & $\mathrm{B}$ & $\mathrm{SE}$ & Beta & $\mathrm{t}$ & Sig. \\
\hline Intercept & 1.682 & 0.092 & & & \\
\hline $\begin{array}{l}\text { Course Delivery } \\
\text { Method } \\
0=\text { Asynchronous, } \\
1=\text { semester-based) }\end{array}$ & $0.529 *$ & 0.254 & 0.058 & 2.086 & 0.037 \\
\hline Gender & 0.117 & 0.108 & 0.03 & 1.078 & 0.281 \\
\hline $\begin{array}{l}\text { Number of Prior } \\
\text { MUHS Online } \\
\text { Courses }\end{array}$ & $0.092 * * *$ & 0.01 & 0.267 & 9.601 & 0.000 \\
\hline $\mathrm{R}^{2}$ & 0.076 & & & & \\
\hline
\end{tabular}

Mirroring the results of the t-tests described previously in the discussion of Table 3, both course delivery method and prior MU High School online course experience have a statistically significant relationship with the grades students earned, while there was no gender difference in student grades. Gender was not significant with $p=0.281$. Course delivery method was significant at $\mathrm{p}<0.05$ level $(\mathrm{p}=0.037)$. The number of prior $\mathrm{MU}$ 
High School online courses taken was also statistically significant at 0.001 level $(p=0.000)$. Results of this multiple regression analysis of SIS data support my third hypothesis.

\section{Course Delivery Method and Course Completion Rates}

The final test performed on data from MU High School's SIS was a logistic regression analysis examining the relationship between course delivery method and completion rates. Logistic regression is similar in many ways to multiple regression, "but with an outcome variable that is a categorical dichotomy and predictor variables that are continuous or categorical...this simply means that we can predict which of two categories a person is likely to belong to given certain other information" (Field, 2005, p. 218).

Results for logistic regression are reported as a Wald statistics value, and can be thought of as a predictor of an outcome. When the Wald value is larger than 3.84 , the p-value or significance level is smaller than 0.05 (Field). Table 6 below displays the results of a logistic regression test which examined the relationship between course type and completion rates. Control variables were gender and prior MU High School online course experience. 
Table 6

Logistic Regression: Relationship between Course Delivery Method and Course Completion Rates Controlling for Student Background Information $(N=1,207)$

\begin{tabular}{|c|c|c|c|c|}
\hline & $\mathrm{B}$ & $\mathrm{SE}$ & Wald & Sig. \\
\hline Constant & -0.124 & 0.110 & 1.279 & 0.258 \\
\hline $\begin{array}{l}\text { Course Delivery } \\
\text { Method }\end{array}$ & $1.313 * *$ & 0.394 & 11.102 & 0.001 \\
\hline Gender & 0.075 & 0.124 & 0.366 & 0.545 \\
\hline $\begin{array}{l}\text { Number of Prior } \\
\text { MUHS Online } \\
\text { Courses }\end{array}$ & $0.132 * * *$ & 0.017 & 61.137 & 0.000 \\
\hline Cox \& Snell $\mathrm{R}^{2}$ & 0.082 & & & \\
\hline
\end{tabular}

The results of this logistic regression indicate that there is a statistically significant relationship between course delivery method and the likelihood of completing online coursework with a Wald statistics value of 11.102 and a significance level of $\mathrm{p}<0.001$. This $\mathrm{p}$ value indicates that we can be $99.9 \%$ confident that the slope of the relationship is significantly larger than 0 . There is also a statistically significant relationship between prior online course experience and the likelihood of completing online coursework with a significance level of $\mathrm{p}<0.000$. There is no gender difference in the likelihood of completing online courses.

Previous literature pointed out that high attrition rates have long been a concern of distance learning courses. For example, Barbour and Reeves (2009) and Zucker and Kozma (2003) described the large number of distance education students that drop out of their courses at all levels, with Zucker and Kozma also finding a higher percentage of 
online students not completing or dropping online courses compared to similar face to face courses. Hannum et al. (2008) have shown that timing and pacing of distance education courses combined with student motivation are contributing factors in distance education attrition rates. Based on the results in Table 6 above and the chi-square test summarized previously in Table 3, one could speculate that in semester-based courses with increased interaction and communication between students, an increased sense of community may result in fewer students withdrawing from their coursework.

\section{Summary}

This study explored the relationships between course delivery methods and students' experiences in high school online courses and their academic success. For this quasi-experimental study, I posed three research questions relating to online courses students took through the University of Missouri High School, or MU High School.

Based on the data received from the survey respondents, no significant difference was found between students in asynchronous online courses and semester-based online courses in regard to their learning experiences. Therefore, the data did not support hypothesis one.

Using multiple regression analysis of seven different measures of student satisfaction, research question two was tested. Students in asynchronous and semesterbased courses rated their satisfaction with their online course's instructor, structure, content, assessments, materials, communication with classmates, and overall quality. Of these seven measures, the only one that showed a statistically significant difference was 
communication with classmates — not an unexpected result since there is a lack of communication with classmates during asynchronous courses. Based on their survey responses and for this particular group of students being surveyed, hypothesis two is not supported.

Final grades that students earned in their online coursework and completion rates comparing students in asynchronous with semester-based courses were examined to test research question three. The multiple regression analysis showed that students in semester-based courses earned higher grades than their asynchronous counterparts. Likewise, the multiple logistic regression analysis showed that students in semester-based courses had a much higher completion rate compared to asynchronous students. Therefore, hypothesis three is supported.

Chapter Five will further discuss the results of this study and implications for theory and practice. Limitations of the study and how those limitations may have affected results will be addressed, as will recommendations for future research and leadership practice. 


\section{CHAPTER 5: DISCUSSION OF RESULTS}

\section{Summary of the Study}

In this dissertation research, online courses at the University of Missouri High School were examined regarding the relationships between the course delivery method and student course experiences, satisfaction, and academic achievement (course grades and completion rates). This topic was chosen because of the rapid expansion of online education. Despite the growth of this type of educational delivery, there is a lack of research, especially experimental and quasi-experimental research, on the topic at the high school level.

The previous chapters introduced a literature review, three research questions and corresponding hypotheses, the quasi-experimental methods used to test the questions, the data obtained during the study, and statistical analysis results. This chapter will discuss the results in further detail, relating the results to the research questions posed and the literature review. Implications for schools offering distance education to their students and recommendations for leaders of such schools will be presented.

\section{Discussion of Results}

An online course survey was developed and sent to students who completed online courses through MU High School during the 2009-2010 academic year and the fall 2010 semester. Thirteen semester-based students responded to the survey, while 37 
students in asynchronous courses completed it. Given the small number of students who participated in the survey even with incentives for completing it provided, additional information on enrollments, course grades earned, and course completion rates were obtained from the school's SIS. All variables in the survey and obtained through the SIS were coded so that the data could be analyzed using SPSS 19.0. The three research questions posed for the study are presented in the next few sections, along with a summary of statistical analysis results addressing these questions.

\section{Course Experiences}

The first research question asked "how do learning experiences of high school students in semester-based courses differ from those of students in asynchronous courses?”. In MU High School's asynchronous courses, there is no real-time interaction between instructors and students, and no communication between other students.

Although students can and sometimes do email instructors with questions, the majority of students do not, and instead rely on the instruction provided to them only through the online course content. Semester-based courses, on the other hand, run on a semester calendar, have due dates for assignments, and have scheduled communication between instructors and students. To analyze how course type (asynchronous or semester-based) influenced student experiences with online courses, t-tests were conducted, thereby comparing the means of the two groups of students. Asynchronous and semester-based student responses were compared for each of the following survey summary variables: cognitive and metacognitve, motivational and affective, developmental and social, and individual differences. In summary, there was no statistically significant difference found between the two groups of students for any variable examined. 
Although not significant, recall that the largest t-value of all survey variables displayed in Table 3 was the summary variable for individual differences factors with a tvalue of 1.32. It is logical that students in asynchronous courses would value individualistic characteristics such as flexibility of scheduling in the course they choose to enroll in, while students who want a more communal learning experience with their instructor and fellow classmates would be more likely to enroll in semester-based courses. If this is the case, then why were the means of the two groups of students not statistically significant? The fact that students did not show any difference, at least from student perspectives, is puzzling.

A possible explanation for the lack of significance could be that semester-based courses with a more structured schedule and more interaction did not necessarily create a better learning experience for students. Perhaps the instructor did not teach differently for the two types of course delivery methods. For example, many of the instructors for semester-based courses also serve as the instructor for the corresponding asynchronous course title. It is possible that individual teachers teach in the same manner, regardless of the delivery method and environment they are teaching in. It is possible that teachers deliver these courses in a similar manner, and thus, not creating unique differences that give students an advantage in their learning experiences.

\section{Course Satisfaction}

The second research question asked "are students in semester-based online courses more satisfied with their course experience than the students in asynchronous online courses?". This question was also tested using student survey responses. Specifically, seven aspects of students' satisfaction with their coursework (instructor, 
structure, content, assessment, materials, communication, and quality) were examined regarding their relationship with the course delivery method, controlling for parents' education level, prior online course experience, and comfort level with online courses.

The only significant difference by course type in any of the seven measures of student satisfaction was for communication, which is not surprising given the fact that there is no communication between classmates in the asynchronous courses. There was no statistical significance between the two groups of students for any of the other six measures of student satisfaction. Consequently, hypothesis two that projected students in semester-based online courses would be more satisfied with their course experience than the students in asynchronous online courses is also not supported.

Much like the results of my first research question and hypothesis that was not supported, one is again left to wonder why there is such a lack of significance in the results as reported by students for this second research question regarding student satisfaction. Is it possible that students got what they expected because of the course they chose to enroll in, and hence, they had similar levels of satisfaction despite the different method of course delivery? Or perhaps there was such little difference in the instructor's approach regardless of course delivery method (as speculated in the previous section) that satisfaction levels were similar between both asynchronous and semester-based students.

In general, both asynchronous and semester-based students were satisfied with their online coursework through MU High School. This is very much in line with the results of a study by the Southern Regional Education Board (SREB) which found that $80 \%$ of more than 2,000 middle and high school students felt academically prepared to take online courses and that their coursework was well designed (Thomas, 2008). 
Seventy-eight percent of the students felt their instructor communicated well with them and answered their questions quickly, and $68 \%$ of them liked their online courses. My results were also in line with survey data from 50 Canadian secondary students who were generally satisfied with their online learning experience because of the autonomy and flexibility that online learning affords them, although students reported they had difficulties with time management (Tunison \& Noonan, 2001). It is possible that the autonomy and flexibility of asynchronous courses is counterbalanced by the increased structure and scheduling of semester-based courses, although the literature reviewed in this study did not disaggregate such information. To better pinpoint factors that influence student satisfaction with their online coursework in the future, it might be helpful to assess student expectations prior to beginning an online course, as well as assess how well those expectations were met upon course completion.

\section{Student Achievement: Course Grades \& Completion Rates}

Assessing student experiences and satisfaction with online coursework can only be acquired through questions directly asked of the students by such means as a survey. However, the number of students who opted to complete the survey was small. Consequently, to examine the issue of if and how course delivery methods are associated with student grades and completion rates, information was obtained from a much larger pool of data from MU High School's SIS for all enrolled students in the targeted groups.

The third research question asked if students in semester-based online courses perform better and have a higher completion rate than students enrolled in asynchronous online courses, controlling for previous online course experience and student gender. Course grades as a proxy of student achievement were analyzed with both a t-test and 
multiple regression. Chi-square and multiple regression tests were used to examine course completion rates.

The mean letter grade score of asynchronous students was 2.21, compared to 2.92 among semester-based students. The multiple regression analysis results showed that students in semester-based courses received higher grades than the students in asynchronous courses, controlling for gender and previous online course experience with a significance level of $\mathrm{p}<.05(\mathrm{p}=0.037)$.

Raw percentages of course completion rates show that $86.2 \%$ of students in semester-based courses completed their online coursework, compared to a much lower rate of $62.4 \%$ of students in asynchronous courses. The multiple logistic regression analysis also showed that students in semester-based courses have a significantly higher possibility of completing the course than the students in comparable asynchronous courses.

All four SPSS tests performed (t-test, multiple regression, chi-square, and logistic regression) showed a significant difference in student achievement between those students enrolled in asynchronous and semester-based courses, with semester-based students achieving at a higher level. Therefore, hypothesis three that posited students in semester-based online courses achieve higher and have higher completion rates than the students in asynchronous online courses is supported.

Not all research done previously on the timing and synchronicity of distance learning, however, has had similar results. In a meta-analysis of 232 empirical studies, Bernard et al. (2004) found that students enrolled in synchronous distance education modes did not perform as well as their classroom counterparts, while students enrolled in 
asynchronous distance education courses had higher levels of achievement compared to students in a classroom setting. There are major differences with the parameters of Bernard's study and this dissertation study, however. Bernard was specifically studying synchronous videoconferencing and audioconferencing modes of distance education delivery, and he was comparing these to traditional classrooms, which are also inherently synchronous. My study, on the other hand, compares asynchronous online courses to semester-based courses with synchronous communication components.

Although the relationship between course delivery method and student achievement as measured by final course grades and completion rates is significant in my study, it is important to point out that the relationship is not necessarily causal. While students in semester-based courses achieve at higher levels, it is also possible that results are due to another factor, or more likely, a combination of multiple factors, as is the case with any form of education. For example, although students did not necessarily feel they made a difference, perhaps scheduled chats and interaction with their instructor and other students affected their achievement. It is possible that the interaction and the additional structure that comes from having due dates for assignments helped the semester-based students achieve at a higher level and have higher course completion rates, even though the students did not necessarily reflect this in their survey responses. This supposition is supported by Bernard et al.'s (2004) recommendations based on his meta-analysis that distance learning should include interactivity and collaborative opportunities between students, including the use of technologically mediated communication tools.

Another factor that may have contributed to higher course grades and completion rates for semester-based students is that of student self-selection of course delivery 
method. Could it be that the student who decides to enroll in a semester-based course is higher achieving to begin with? This may not be the case, however, based on their similarities to asynchronous students in terms of the student background information gathered, such as parents' educational level—a measure often used as a predictor for their children's academic achievement. It would be interesting to study, however, who these students are that self-select to enroll in semester-based courses and why. Again, it may be useful to do a pre-assessment of more detailed student information to determine if factors such as previous academic performance may be associated with students' online course selection and academic performance in their online coursework. Alternatively, there may be no differences in the types of students that choose semester-based versus asynchronous online coursework, but rather the additional course structure and communication of semester-based courses may help encourage students to achieve at a higher rate and follow through to course completion.

\section{Implications for Theory and Practice}

As was discussed in Chapter Two, the research on distance education at the high school level has been sparse, and what little has occurred was primarily aimed at comparing it to traditional face to face education (Cavanaugh et al., 2009; Picciano \& Seaman, 2009; Reeves, 2005; Rice, 2006; Schlosser, 1996). Studies such as this one help to overcome those problems, in addition to comparing the effectiveness of alternative forms and methods of distance education, specifically at the high school level (Pittman, 2003). This research is needed to look at student learning experiences and the 
effectiveness, strengths, and weaknesses of different methods of distance learning (Nasseh, 1997). This section will discuss possible implications of how the results of this dissertation study can influence theory and practice.

Implications for theory include referring back to the theoretical framework of the APA's Learner-Centered Principles presented earlier as they pertain to distance learning. For example, not only should online course design consider the content, or the cognitive and metacognitive aspects of coursework, but courses should also be designed with considerations for the other three factors of the Learner-Centered Principles: motivational and affective, developmental and social, and individual differences. For instance, in the motivational and affective domain, individual students' levels of motivation, their personal goals, and their satisfaction levels may all be affected by course design although students did not necessarily self-report these relationships on the surveys they completed.

For this particular study in comparing the student experiences of semester-based and asynchronous online learners, there was no significant difference based on the results obtained from surveys assessing student opinions. This result implies that having increased options for students so they can self-select which mode of learning works best for their particular learning style and situation is an advantage, and also marries well with the theoretical framework factor of considering students' individual differences. Even if individual students may learn better with a calendar and the developmental and social factors of increased communication with the instructor and communication between students, that does not mean such circumstances are always available as an option. Scheduling problems, including health issues, travel, work, or training schedules may prevent students from being able to adhere to a calendar. In a study of Canadian middle 
schoolers, Litke (1998) found students appreciated the flexibility and decreased distractions of a virtual setting, but students also noted that online learning was not for everyone and personal traits such as motivation, sense of independence, and organizational skills are important contributing factors in determining students' academic success. Consequently, providing students with greater options in their choices of online coursework and its design, may help students have a more positive learning experience overall.

There are also implications of this study's results for leaders of distance education to consider, and these implications are intertwined with the theoretical ones. Comparing satisfaction levels of asynchronous to semester-based students yielded no statistical difference in six of seven categories based on student survey responses. Again, this could be related to students self-selecting course type based on either what they would prefer or on their scheduling needs. Students in this study generally rated their satisfaction levels as high. For this dissertation study, the only measure of student satisfaction that showed a statistically significant difference was communication with classmates, with asynchronous students scoring an expected lower level of satisfaction. Based on the results of Bernard et al.'s (2004) study looking at achievement of distance education students, his group recommended that distance learning coursework should include collaboration between students and opportunities for communication and interactivity, which reinforces the implication that distance education school leaders should consider developmental and social factors in the education of their students. Data to test achievement by looking at course grades and completion rates was obtained directly from the SIS database, which was a much larger experimental group of students than those 
who chose to respond to a survey. Results of this study's SIS data support Bernard's claim since students in semester-based courses with increased communication had higher course grades and completion rates compared to students in asynchronous courses.

Individual preferences, learning styles, and needs of students are still factors though, regardless of the experimental group's size and quantity of data. Tunison and Noonan (2001), for example, found that even with use of communication tools such as email, bulletin boards, and chat rooms in their online courses, students still did not use them much although they recognized the value of such communication tools. Litke's (1998) claims that personal characteristics like motivation, organization skills, and ability to work independently are all factors influencing student achievement. This is true regardless of course type, and ties in well with the assertion that students have individual learner preferences and needs.

Some students may feel they need greater course structure with due dates and increased interaction with their instructor and other students. This, in turn, may lead to a greater sense of community and belonging, thereby resulting in higher grades and course completion rates. This idea is supported by Litke (1998) who also found that deterrents to virtual learning included feelings of isolation, and in some cases, decreased contact with teachers and other students. Other students though may prefer, and even thrive, given increased flexibility of scheduling and the independence to work on their own (Barbour \& Reeves, 2009; Bower \& Hardy, 2004; Cavanaugh et al., 2009; Mupinga, 2005; Riche, 2006).

In summary, leaders of distance education schools should consider the implications of not only the cognitive and metacognitive factors of the Learner-Centered 
Principles, but also those of motivational and affective factors, developmental and social factors, and individual differences factors. Providers of distance learning coursework have primarily concerned themselves with the content, that is, the cognitive aspects of course design, and rightfully so. However, this study and others have revealed additional and sometimes more subtle implications for online coursework. For example, providing options in the flexibility of course scheduling and communication with their instructor and other students should be considerations when designing and delivering online coursework to students.

\section{Limitations of the Study}

While this study examined a very specialized situation within the context of a distance learning environment, limitations exist precisely because of the distance learning environment and inherent difficulties in attempting to study students at a distance. For example, with students scattered across the globe, it makes it difficult to convince them that their opinions are important enough to warrant their completing a survey. The response rate to a student survey was extremely low, especially from asynchronous students. While the response rate was better for semester-based students, there was a much smaller group to solicit for participation from the onset. Small sample size and a disproportionate response rate between semester-based and asynchronous students were limitations for this study. Although additional data on student grades beyond the student survey were obtained from the SIS, the distance factor made it impossible to get further information on previous academic performance at their own high school, and more 
difficult to control for other variables. Future research should seek out methods for increasing student participation, such as providing better, more attractive incentives for students. Perhaps a few students could be interviewed so as to learn what would motivate them to complete a survey. Another option would be to survey the students before they complete their coursework while they are still actively engaged in their studies. Students may have more "buy-in" if they perceive the research as being more timely, and thus, more relevant to them.

Additionally, the study was nonrandomized because students self-selected which courses they chose to enroll in. This selection bias in turn could be linked to student performance and achievement. Do students self-select a particular course or type of course because of their academic performance, or vice versa? Without access to prior academic performance, it is impossible to know.

As mentioned previously, the setting where the study occurred is highly specific to that of a high school distance education program located on the campus of a land-grant university. Such specificity makes it difficult to generalize results to other distance learning programs, each with a myriad of their own unique circumstances and variables. To further illustrate this point, MU High School is the only university-based program that is currently known to even offer both asynchronous and semester-based course titles. Finally, the researcher performing the study is employed at the site of investigation. Although every effort was made to minimize it, researcher bias is a possibility with every research project, and especially so when the researcher is connected in some manner to the study and its results. 


\section{Recommendations for Future Research}

More research is still needed in the field of online distance learning at the high school level, especially since studies on online learning have been primarily focused on postsecondary education (Picciano \& Seaman, 2009). K-12 distance education is growing at a phenomenal rate, but without an adequate research base to identify and support best practices. It is not appropriate to rely on research performed on adults and college-aged students, nor is it appropriate to generalize results to K-12 learners (Barbour \& Reeves, 2009; Rice, 2006). Additionally, much of the research has been anecdotal, comprised of personal opinions, or advice intended to assist other educators as they develop distance learning (Moore \& Thompson, 1990).

While this study added to the experimental and quasi-experimental research base of pre-collegiate online learning, the results are context and situation specific, and thus, not highly generalizable. This study did, however, examine specific methods of distance education, and moreover, specific differences in online delivery based on timing and communication with instructor and students. Other researchers have called for the need for such research at the high school level (Pittman, 2003). Still, more research can be done examining student learning experiences, effectiveness of instructional methods, and strengths and weaknesses of different methods of distance learning (Nasseh, 1997).

In reference to online learning, Cavanaugh et al. in 2004 called for research so that we can learn "how to make it more effective, what factors contribute most to effectiveness, and in what contexts the factors operate" (p. 20). This assertion still holds true, and with the growth of online education at the high school level, there will 
eventually be more data and greater opportunities for researchers to explore. Surveys and other information gathering instruments with a high degree of reliability and validity can be developed. Student opinions should be solicited on a larger scale, so as to assess specific details on what does and what does not work for them. Background information on previous student performance and learning styles should be explored, as well as how such factors influence students' online learning experiences and achievement. These implications and possibilities are linked to the individualized and multi-dimensional nature of learning as described by the Learner-Centered Principles discussed in Chapter Two as a theoretical framework. Indeed, the Learner-Centered Principles can be used to further guide online learning research, much like the groundwork performed by McCombs and Vakili (2005). An extension of possible future research is to develop an instrument to predict the suitability of individuals to different modes of course delivery, including different types of online course methodology.

\section{Recommendations for Leadership Practice}

Leaders of distance learning schools are at a crossroads. From personal experience, the researcher involved in this study can attest that it is both exciting and intimidating. The possibilities for online education and the barriers it can be used to overcome are exciting with the potential for unprecedented growth. That same potential creates an overwhelming sense of responsibility and trepidation that comes with traveling murky waters. As noted previously, much research remains to be done. Yet, online course providers are seeing potential profits to be made at the expense of schools and their 
students. Not all providers have the well-being and success of students at heart, and forprofit providers are often of questionable quality. Leaders of distance education schools will therefore benefit from the increased research and knowledge base that is bound to eventually emerge from a greater number of distance learning providers and students taking online coursework.

Based on the results of this dissertation study, one might conclude that online courses should contain a calendar, have due dates for assignments, and allow for increased and scheduled interaction between students and their instructor. Semester-based courses at MU High School contain such features, and students in semester-based courses had higher mean grades and completion rates as compared to students in asynchronous courses. However, certain practical matters should also be considered. For example, offering semester-based courses is much more time and labor intensive than asynchronous courses. In many cases these courses operate at a net financial loss because of the time and labor commitments. Losses could be minimized if semester-courses could at least operate in terms of scalability with a larger volume of enrollments. This is not the case at MU High School, however, and the net loss is further compounded by the fact that many fewer students choose to enroll in semester-based courses than asynchronous ones. In essence, courses that are more costly to deliver are resulting in fewer enrollments. No program can continue to operate at a loss indefinitely. While it is a worthwhile goal to offer courses which students are more prone to succeed in academically, the reality of being able to afford to do so should be considered by leaders of distance education institutions. 
Providing students with increased options to coursework in order to overcome time, location, and access barriers should be at the core of every distance learning provider's mission. In the case of MU High School, it has already been noted that while students in semester-based courses may have higher rates of achievement, that does not equate to those courses being more popular. Therefore, distance learning leaders need to remember the reasons why students choose particular courses are tremendously varied. Being able to offer a variety of courses in different formats and with different scheduling would be ideal. Students could mix and match what they prefer and need. However, as noted with semester-based courses, having increased variety comes at increased costs. Rather than a single online provider trying to "do it all", it might be more cost effective for an online provider to specialize and find a niche market with a target audience.

Finally, leaders of distance education schools should build off of the research that has already been performed. Those providers that have been around since the very beginning of online delivery have not had the luxury of an extensive research base to draw from since this method of course delivery is still fairly new. Greater attention in the future should be paid to best practices as defined by research, but balance has to be maintained between what is ideal and what is cost effective in an online learning environment. The same can also be said of an education obtained in a traditional brick and mortar school building. To help ensure high quality online courses, they should be developed by experienced, certified teachers, and according to state or national learning standards. Internal review and quality control measures should be in place to examine courses for relevance, grade level appropriateness, and user-friendliness. Additionally, 
quality control and external validation should be pursued through appropriate accrediting agencies.

\section{Conclusions}

Online learning at the high school level is growing at an unprecedented rate, yet without a firm foundation of research to adequately build upon. This study contributed to the research base by examining how the experiences, satisfaction levels, and achievement of students in asynchronous online courses compared to students who completed semester-based online courses at MU High School. In summary, based on survey results of 13 semester-based students and 37 asynchronous ones, no statistically significant differences were found for student experiences and satisfaction between the two groups of students. However, information on a much larger pool of students from the school's SIS yielded significant differences when comparing measures of student achievement. Semester-based students had higher course grade means and a higher course completion rate than students in asynchronous courses.

The mixed results of this study further highlight the need for increased experimental and quasi-experimental research on distance learning methodology, and specific factors that influence student experiences and achievement. Further muddying the research waters though are uncontrollable factors such as student preferences, learning styles, scheduling needs, and intrinsic personal characteristics that affect which types of courses students self-select to enroll in, and in turn, their academic success. Much like face to face education in a traditional school setting, online education is 
influenced by a multitude of variables, some of which are beyond the influence of school leaders. Nonetheless, the opportunity is ripe for online learning. The opportunity is ripe and the timing is right for leaders of online schools to conduct quality research, and thus, have a greater impact on their schools and students in the future. 


\section{References}

Alabama Department of Education (2009). High School Distance Learning: Online/Technology Enhanced Course or Experience Guidance. Retrieved April 12, 2010 from https://docs.alsde.edu/documents/61/OnlineGuidance.pdf

APA Work Group of the Board of Educational Affairs. (1997). Learner-centered psychological principles: A framework for school reform and redesign. Washington, DC: American Psychological Association. Retrieved April 12, 2010 from http://www.apa.org/ed/governance/bea/learner-centered.pdf

Barbour, M.K., \& Reeves, T.C. (2009). The reality of virtual schools: A review of the literature. Computers and Education, 52, 402-416.

Bernard., R.M., Abrami, P.C., Lou, Y., Borokhovski, E., Wade, A., Wozney, L., Wallet, P.A., Fiset, M., \& Huang, B. (2004). How does distance education compare with classroom instruction? A meta-analysis of the empirical literature. Review of Educational Research, 74(3), 379-439.

Black, E., DiPietro, M., Ferdig, R., \& Polling, N. (2009). Developing a survey to measure Best practices of K-12 online instructors. Online Journal of Distance Learning Administration, XII(1). Retrieved April 29, 2009, from http://www.westga.edu/ distance/ojdla/spring121/black121.html

Bower, B.L., \& Hardy, K.P. (2004). From correspondence to cyberspace: Changes and challenges in distance education. New Directions for Community Colleges, 124, $5-12$. 
Cavanaugh, C.S., Barbour, M.K., \& Clark, T. (2009). Research and practice in K-12 online learning: A review of open access literature. International Review of Research in Open and Distance Learning, 10(1), 1-22.

Cavanaugh, C., Gillan, K.J., Kromrey, J., Hess, M., \& Blomeyer, R. (2004). The Effects of Distance Education on K-12 Student Outcomes: A Meta-Analysis. Naperville, IL: Learning Point Associates/North Central Regional Educational Laboratory. Creswell, J. W. (2003). Research design: Qualitative, quantitative, and mixed methods approaches $\left(2^{\text {nd }}\right.$ ed.). Thousand Oaks, CA: Sage Publications.

Davis, M.R. (2009). Breaking away from tradition: E-learning opens new doors to raise achievement. In Education Week's Technology Counts 2009 issue, 28(26), 8-11.

Dodd, C., Kirby, D., Seifert, T., \& Sharpe, D. (2009). The impact of high school distance e-learning experience on rural students' university achievement and persistence. Online Journal of Distance Learning Administration, XII(1). Retrieved April 29, 2009, from http://www.westga.edu/ distance/ojdla/spring121/dodd121.html

Edelson, P.J., \& Pittman, V.V. (2001). E-learning in the United States: New directions and opportunities for university continuing education. Global E-journal of Open, Flexible, and Distance Education, 1(1), 71-83.

Field, A. (2005). Discovering statistics using SPSS: And sex, drugs, and rock ' $n$ ' roll ( $2^{\text {nd }}$ ed.). Thousand Oaks, CA: Sage Publications.

Fink, A. (2006). How to conduct surveys: A step-by-step guide $\left(3^{\text {rd }}\right.$ ed.). Thousand Oaks, CA: Sage Publications.

Galvan, J. L. (2006). Writing literature reviews: A guide for students of the social and behavioral sciences ( $3^{\text {rd }}$ ed.). Glendale, CA: Pyrczak. 
Hannay, M. \& Newvine, T. (2006). Perceptions of distance learning: A comparison of online and traditional learning. MERLOT Journal of Online Learning and Teaching, 2(1), 1-11.

Hannum, W.H., Irvin, M.J., Lei, P.W., \& Farmer, T.W. (2008). Effectiveness of using learner-centered principles on student retention in distance education courses in rural schools. Distance Education, 29(3), 211-229.

Herr, K., \& Anderson, G. L. (2005). The action research dissertation: A guide for students and faculty. Thousand Oaks, CA: Sage.

LeBaron, J.F., \& Tello, S.F. (1998). Evaluating the effectiveness of distance education: What should we be asking? Knowledge Quest, 26(3). Retrieved April 29, 2009, from http://gse.uml.edu/lebaron/Evaldl.html

Litke, D. (1998). Virtual schooling at the middle grades: A case study. The Journal of Distance Education 13(2), 33-50.

Kachel, D.E., Henry, N.L., \& Keller, C.A. (2005). Making it real online: Distance learning for high school students. Knowledge Quest, 34(1), 14-17.

Kirby, E. (1998). Administrative issues for high school distance education. Online Journal of Distance Learning Administration, 1(2). Retrieved March 20, 2009, from http://www.westga.edu/ distance/ojdla/summer12/kirby12.pdf

McCombs, B.L, \& Vakili, D. (2005). A learner-centered framework for e-learning. Teachers College Record 107(8), 1582-1600.

Merriam, S. B. (1998). Qualitative research and case study applications in education. San Francisco: Jossey-Bass. 
Moore, M.G., \& Thompson, M.M. (1990). The effects of distance learning: A summary of literature. Penn State University: The American Center for the Study of Distance Education.

Mupinga, D.M. (2005). Distance education in high schools: Benefits, challenges, and suggestions. Clearing House, 78(3), 105-107.

Nasseh, B. (1997). A brief history of distance education. Retrieved April 25, 2009, from http://www.seniornet.org/edu/art/history.html

O’Neal, K. (2009). The comparison between asynchronous online discussion and traditional classroom discussion in an undergraduate education course. MERLOT Journal of Online Learning and Teaching, 5(1), 88-96.

Picciano, A.G., \& Seaman, J. (2009). K-12 online learning: A follow-up survey of U.S. school district administrators. Newburyport, MA: Sloan Consortium.

Pittman, V.V. (2003). Correspondence study in the American university: A second historiographic perspective. In M.G. Moore \& W.G. Anderson (Eds.), Handbook of distance education (pp. 21-35). Mahwah, NJ: Lawrence Erlbaum Associates.

Reeves, T.C. (2005). No significant differences revisited: A historical perspective on the research informing contemporary online learning. In G. Kearsley (Ed.), Online learning: Personal reflections on the transformation of education (pp. 296-305). Englewood Cliffs, NJ: Educational Technology Publications.

Rice, K. (2009). Priorities in K-12 distance education: A Delphi study examining multiple perspectives on policy, practice, and research. Educational Technology \& Society, 12(3), 163-177. 
Rice, K.L. (2006). A comprehensive look at distance education in the K-12 context. Journal of Research on Technology in Education, 38(4), 425-448.

Roblyer, M.D., \& Marshall, J.C. (2003). Predicting success of virtual high school students: Preliminary results from an educational success prediction instrument. Journal of Research on Technology in Education, 35(2), 241-255.

Rossi, P. H., Lipsey, M. W., \& Freeman, H. E. (2004). Evaluation: A systematic approach $\left(7^{\text {th }}\right.$ ed.). Thousand Oaks, CA: Sage.

Saba, F. (2000). Research in distance education: A status report. International Review of Research in Open and Distance Learning, 1(1), 1-9.

Schlosser, C. (1996). Distance education: What the literature says works. $26^{\text {th }}$ Annual Frontiers in Education, vol. 2, 533-555.

Shachar, M., \& Neumann, Y. (2003). Differences between traditional and distance Education academic performances: A meta-analytic approach. International Review of Research in Open and Distance Learning, 4(2). Retrieved February 24, 2009, from http://www.irrodl.org/index.php/irrodl/article/view/153/704

Sher, A. (2008). Assessing and comparing interaction dynamics, student learning, and satisfaction within web-based online learning programs. MERLOT Journal of Online Learning and Teaching, 4(4), 446-458.

Smalley, K.D. (2005). The University of Missouri-Columbia High School: From independent study to accredited diplomas online. In Z.L. Berge \& T. Clark (Eds.), Virtual schools: Planning for success (pp. 159-171). New York: Teachers College Press. 
Thomas, W.R. (2008). Do online courses work for middle grades and high school students? Online students have their say. A Southern Regional Education Board report. Atlanta, GA: SREB. Retrieved April 29, 2009, from http://www.sreb.org/publications/2008/08T05_Onl_Student_Survey.pdf

Tunison, S., \& Noonan, B. (2001). Online learning: Secondary students’ first experience. Canadian Journal of Education, 26(4), 495-511.

United States Distance Learning Association (2009). USLDA About Us web site. Retrieved February 9, 2010, from http://www.usdla.org/html/aboutUs/vmd.htm U.S. Department of Education, Office of Planning, Evaluation, and Policy Development, (2009). Evaluation of evidence-based practices in online learning: A metaanalysis and review of online learning studies. Washington, DC: U.S. Department of Education.

Watson, J. F., Winograd, K., \& Kalmon, S. (2004). Keeping pace with K-12 online learning: A snapshot of state-level policy and practice. Naperville, IL: Learning Point Associates.

WCET. (2008). No significant difference phenomenon. Retrieved October 13, 2008 at http://www.nosignificantdifference.org/

Welch, S.R. (December, 1993). The effectiveness of the home study method. National Home Study Council Occasional Paper. Washington, DC: National Home Study Council.

Zucker, A., \& Kozma, R. (2003). The virtual high school: Teaching generation V. New York: Teachers College Press. 


\section{Appendix A}

\section{Screenshots of Dummy Student Record from MU High's SIS}

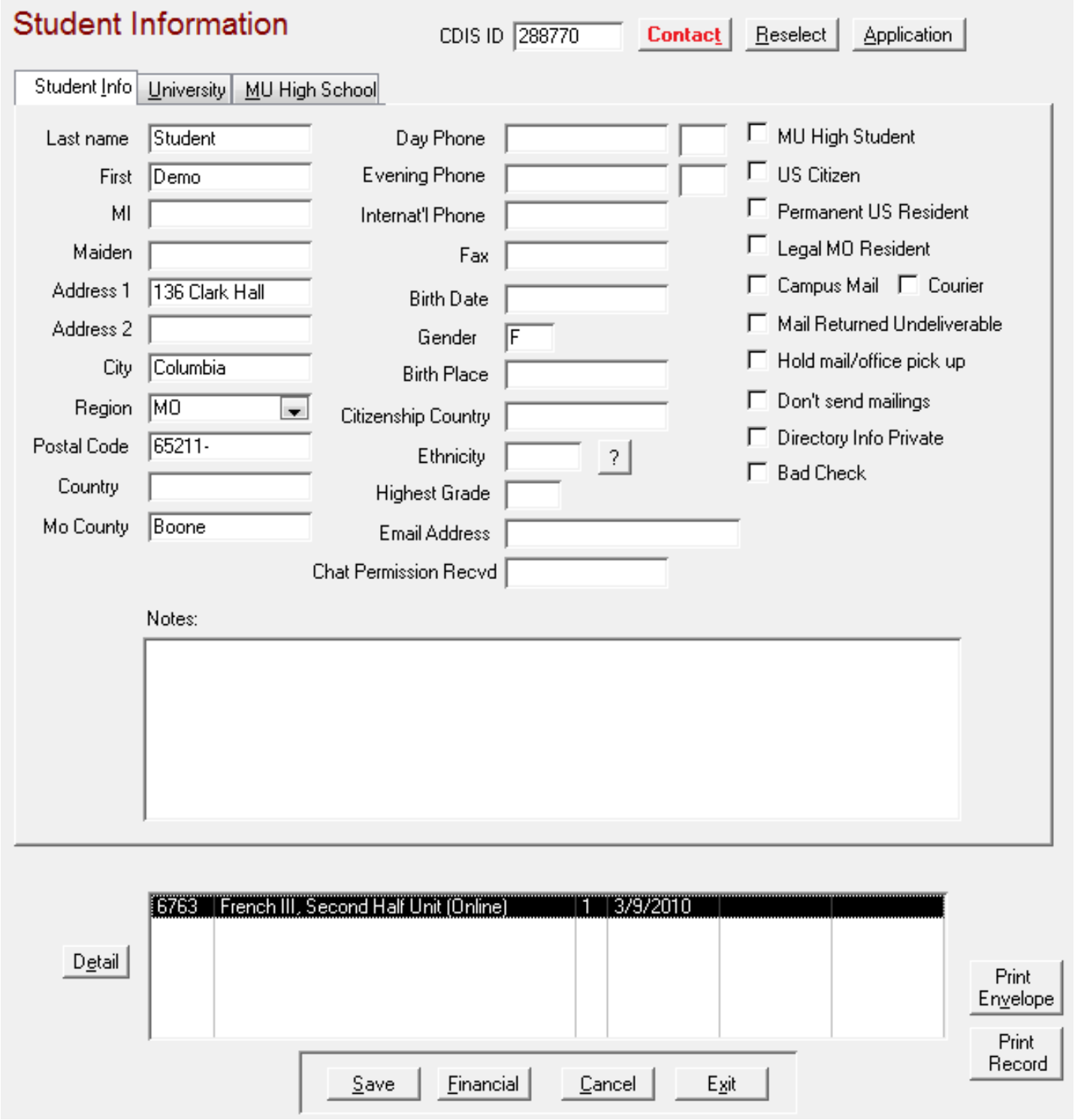




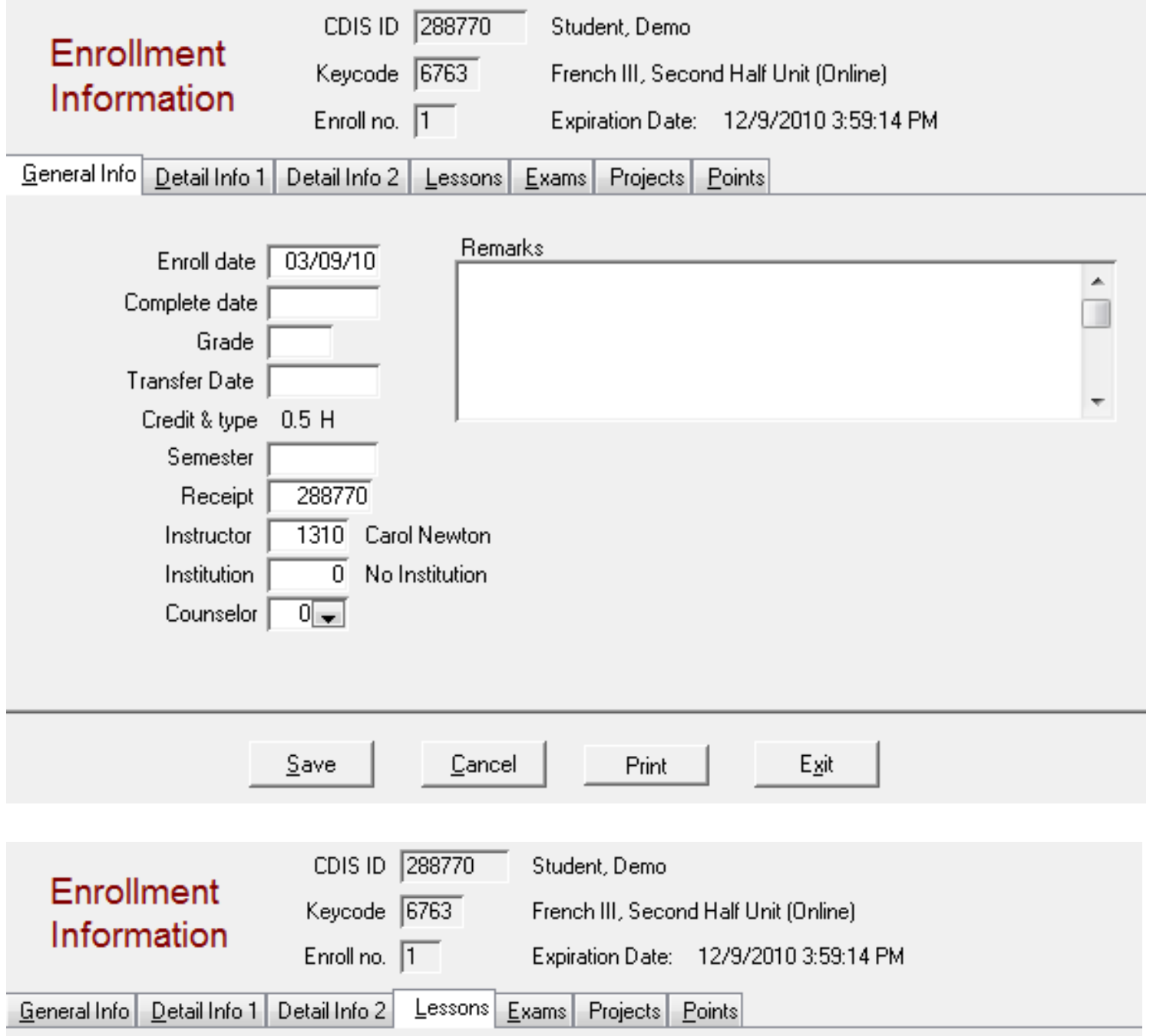

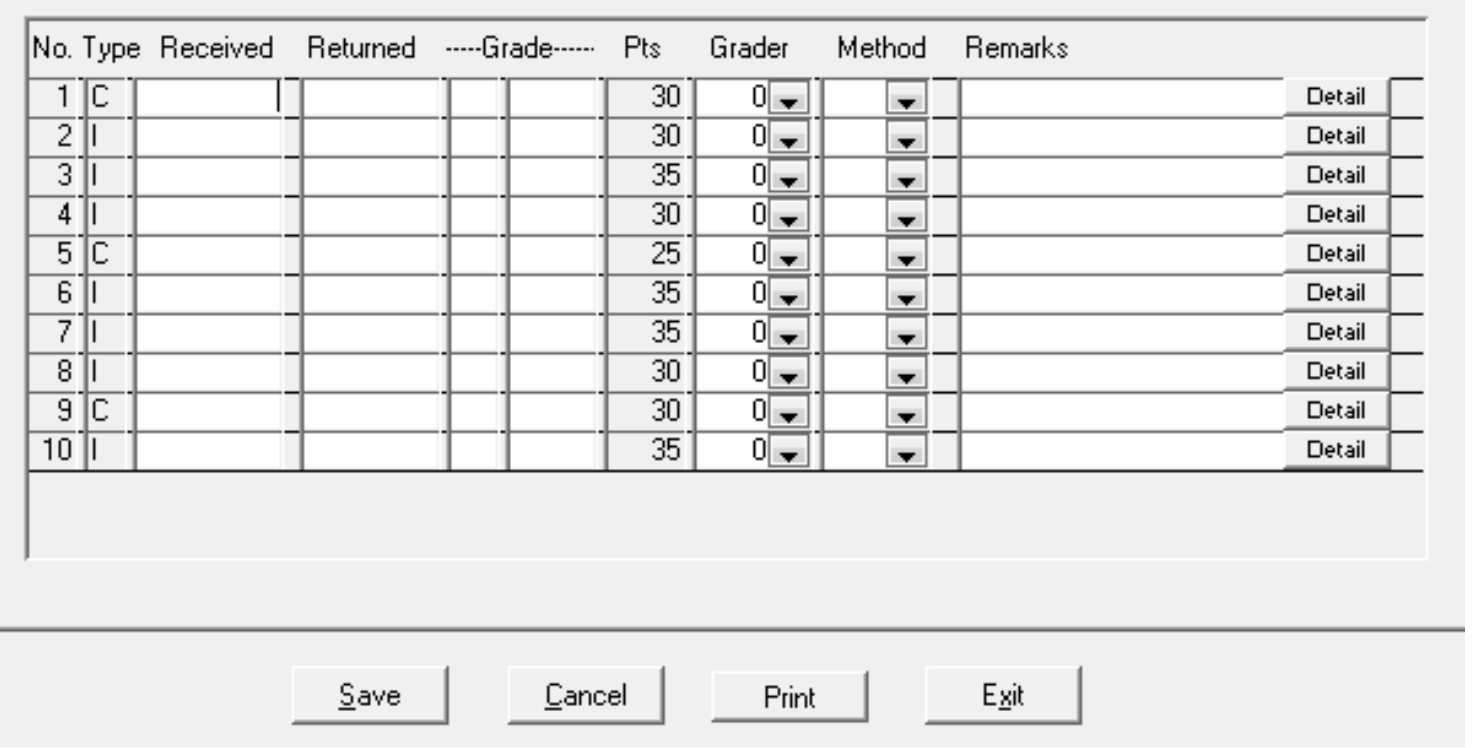




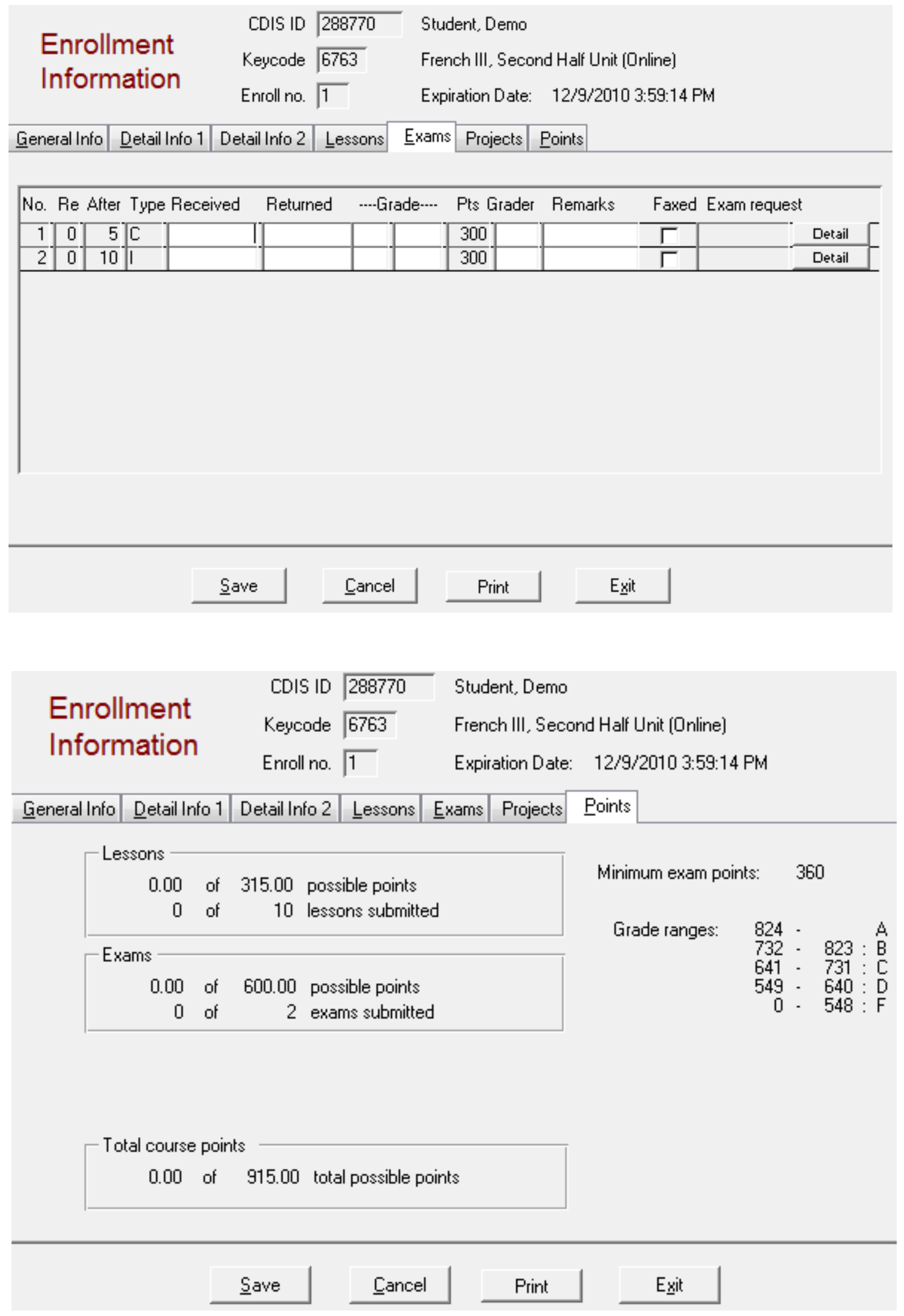




\title{
Appendix B
}

\section{Survey Consent Letters, Recruiting Message \& Directions, and Complete Survey}

\begin{abstract}
All semester-based students and those asynchronous students selected to participate were sent consent letters approximately two weeks before surveys were sent. Because some students were minors, parental consent letters, youth consent letters, and parental consent forms were sent to those students under the age of 18 . Students 18 and over were sent student consent forms. All letters and the recruiting email message with directions for survey completion were approved by the University of Missouri's institutional review board.
\end{abstract}


February 22, 2011

\section{Dear Parent/Guardian:}

I am sending this letter to let you know about a survey on MU High online courses. The purpose of this survey is to understand students' learning experiences with online courses and examine the effectiveness of course delivery methods (e.g. semester-based, asynchronous). Your son or daughter has completed one or more online courses through MU High School during the past year. I would like to make you aware of an upcoming invitation for your son/daughter to participate in an online survey asking for his/her opinions.

The invitation will be sent to your son/daughter by email in approximately two weeks. The survey should take no more than 15 minutes to complete. Students are not required to complete this survey as their participation is completely voluntary. Their answers will be kept strictly confidential, and their participation will not affect their grades in either past, present, or future coursework through MU High School. To protect the identity of students and avoid perceived pressure to complete the survey, another staff member with no conflict of interest will match student records with survey results so that I as principal cannot identify individual students.

Should students choose to complete and submit the entire survey, they will receive a $\$ 5$ Amazon gift certificate as a thank you gift for their time. Students completing the survey will also be entered into a drawing for a chance to win an additional $\$ 75, \$ 50$, or $\$ 25$ gift certificate. Gift certificates will be sent to them either by mail or email.

I hope that you and your son/daughter approve the survey, and that he/she will complete it. The more participants who complete the survey, the more information I can gather to improve the quality of online courses at MU High. If, however, you should choose not to have your child participate, please let me know or disregard the invitation. Thank you for your time and consideration.

If you have any questions about this survey, please contact me at 573-882-4054 or smalleyk@missouri.edu. My advisor, Dr. Motoko Akiba, can be reached at akibam@missouri.edu. For questions about the rights of research participants, please contact the Campus Institutional Review Board (573-882-9585 or umcresearchcirb@missouri.edu). The IRB number for this project is 1178397.

Sincerely,

Kristi Smalley, Principal 
February 22, 2011

Dear Student:

I am sending this letter to let you know about a survey on MU High online courses. The purpose of this survey is to understand students' learning experiences with online courses and examine ways that courses are delivered. You have completed one or more online courses through MU High School during the past year. I would like to make you aware of an invitation to take an online survey asking for your opinions on MU High School courses.

The invitation will be sent to you by email in approximately two weeks. The survey should take no more than 15 minutes to complete. You are not required to complete this survey. Participation is completely voluntary. Answers will be kept confidential. Your participation will not affect your grades in either past, present, or future courses with MU High School. To protect your identity and to avoid perceived pressure to complete the survey, another staff member will gather data for me so that I as principal cannot identify individual students.

Should you choose to complete and submit the survey, you will receive a \$5 Amazon gift certificate as a thank you gift for your time. Students completing the survey will also be entered into a drawing for a chance to win an additional $\$ 75, \$ 50$, or $\$ 25$ gift certificate. Gift certificates will be sent either by mail or email.

I hope that you will complete the survey. The more information that can be gathered to improve online courses at MU High, the better. If you choose not to participate, please ignore the invitation. If you have any questions about this survey, please contact me at 573-882-4054 or smalleyk@missouri.edu. My advisor, Dr. Motoko Akiba, can be reached at akibam@missouri.edu.

The Campus Institutional Review Board approved this research study. You may contact the Campus Institutional Review Board if you have questions about your rights, concerns, complaints or comments as a research participant. You can contact the Campus Institutional Review Board directly by telephone or email to voice or solicit any concerns, questions, input or complaints about the research study.

483 McReynolds Hall, Columbia, MO 65211 (573)882-9585

E-Mail: umcresearchcirb@missouri.edu

Website: http://www.research.missouri.edu/cirb/index.htm

The IRB number for this project is 1178397 . Thank you for your time.

Sincerely,

Kristi Smalley, Principal 


\section{PARENTAL CONSENT FORM}

Title of the Study: MU High School Online Course Survey

Invitation to Participate: Your child is being asked to participate in an evaluation of MU High School's online courses at the Center for Distance and Independent Study. The purpose of the evaluation is to gather information on online courses, student learning preferences, and student achievement. If you have questions about the research or the survey, please contact Kristi Smalley, MU High School Principal, (136 Clark Hall, Columbia, MO 65211; 573-8824054; smalleyk@,missouri.edu).

Procedures: If your consent and your child's assent is given, a survey will be sent to your child that includes questions about general and specific independent study course experiences, learning styles, and student perceptions of their online course experiences.

Risks: You have a right to be informed of all potential risks associated with your child's participation in this research. There are no reasonably foreseeable risks or discomforts that might occur as a result of your child's participation in this research project.

Benefits: As a result of participation, your child's awareness about his or her learning style and independent study course experiences may be increased. The evaluation provides the Center for Distance and Independent Study with valuable insights into the high school program.

Disclaimer/Withdrawal: Your child's participation in this research is completely voluntary and he/she may withdraw at any time. A parent or guardian can also decide that the child can withdraw from the study. Your child will not be required to answer every question that might be asked. This means your child is free to stop participating at any point without penalty or loss of privilege, except for benefits directly related to their participation in this study. Our survey should take only 10-15 minutes to complete.

Alternatives: You may choose to not allow your child to participate in this study. If so, he/she will not be sent a survey. Failure to participate in the evaluation will have no effect on your child's grades or student services for any current or future coursework with MU High School and the Center for Distance and Independent Study.

Compensation: Should you and your child decide to take the survey, they will receive a $\$ 5$ gift certificate as a token of our appreciation. All participants taking the survey will also be entered into a raffle drawing to receive a $\$ 75$, $\$ 50$, or \$25 gift certificate.

Confidentiality: All information collected in this study will be kept confidential and your child will not be identified by name. Survey results will be reported in summary form only. The researcher will keep the completed surveys in a locked filing cabinet for 3 years.

Subject Rights: If you have questions about your child's rights as a participant in this study, please contact the University of Missouri Campus Institutional Review Board (483 McReynolds Hall, Columbia, MO 65211, 573-8829585, umcresearchcirb@,missouri.edu). The IRB number for this project is 1178397.

Conclusion: You have been given the opportunity to ask questions and have had them answered to your satisfaction. You have read and understand the consent form. You agree to allow your child,

(fill in your child's name on the line above) , to participate in this research study.

Please keep one copy of this consent form. Sign and return the other copy of the consent form in the postage paid envelope provided. Thank you.

Name of Parent/Guardian (signature)

Date

Name of Parent/Guardian (print)

Please check this box to indicate your permission to access your child's grades for research purposes. Thank you. 
February 22, 2011

Dear Student:

I am sending this letter to let you know about a survey on MU High online courses. The purpose of this survey is to understand students' learning experiences with online courses and examine the effectiveness of course delivery methods (e.g. semester-based, asynchronous). You have completed one or more online courses through MU High School during the past year. I would like to make you aware of an upcoming invitation for you to participate in an online survey asking for your opinions.

The invitation will be sent to you by email in approximately two weeks. The survey should take no more than 15 minutes to complete. You are not required to complete this survey as participation is completely voluntary. Answers will be kept strictly confidential. Your participation will not affect your grades in either past, present, or future coursework through MU High School. To protect the identity of students and avoid perceived pressure to complete the survey, another staff member with no conflict of interest will gather data for me so that I as principal cannot identify individual students.

Should you choose to complete and submit the survey, you will receive a \$5 Amazon gift certificate as a thank you gift for your time. Students completing the survey will also be entered into a drawing for a chance to win an additional $\$ 75, \$ 50$, or $\$ 25$ gift certificate. Gift certificates will be sent either by mail or email.

I hope that you will complete the survey. The more information that can be gathered to improve the quality of online courses at MU High, the better. If, however, you should choose not to participate, please disregard the invitation. If you have any questions about this survey, please contact me at 573-882-4054 or smalleyk@missouri.edu. My advisor, Dr. Motoko Akiba, can be reached at akibam@missouri.edu. The Campus Institutional Review Board approved this research study. You may contact the Campus Institutional Review Board if you have questions about your rights, concerns, complaints or comments as a research participant. You can contact the Campus Institutional Review Board directly by telephone or email to voice or solicit any concerns, questions, input or complaints about the research study.

483 McReynolds Hall, Columbia, MO 65211 (573)882-9585

E-Mail: umcresearchcirb@missouri.edu

Website: http://www.research.missouri.edu/cirb/index.htm

The IRB number for this project is 1178397 . Thank you for your time and consideration.

Sincerely,

Kristi Smalley, Principal 


\section{Recruiting Email Message and Directions for Survey}

The message below will be sent by email to all students who completed one or more of the selected online courses for this study from MU High School. This recruiting message and cover letter email also included directions on how to access and complete the survey. Some open-ended questions have been included. Although the open-ended questions may not be analyzed statistically, it is hoped they will provide some specific suggestions for improvement or tell us what aspects of MU High School students found most helpful. No fewer than three follow-up email messages were sent to those students who have not completed the survey in hopes of increasing the response rate.

Dear Student:

The purpose of this survey is to learn from your online learning experiences for improving the quality of our courses and services for future students.

You can access the online survey at (URL). It will take about 10-15 minutes to complete the survey.

Your participation in this survey is voluntary, but should you choose to complete it, your answers will be kept strictly confidential. Results will be reported at school level, and no individual responses will be revealed. Your participation in this survey does not affect your grades.

Your opinion is very important to us. Please be as honest and specific as possible. Please return the survey by insert date ( 3 weeks after sending out survey information).

Thank you for helping us improve MU High School, and thus, helping future students. We appreciate your honest opinions and suggestions.

Sincerely,

Kristi Smalley, Principal

MU High School 


\section{MU High School Online Course Survey}

\section{1. of 6 pages}

1. Directions: Please choose your answers by selecting the most appropriate response for each question.

Now, please think about the particular MU High School course you took during the 20092010 school year to answer the following questions. The name (or title) of the online course you took through MU High School was [CustomData]

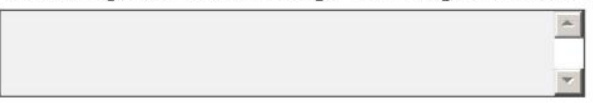

2. Please indicate the extent to how much you agree or disagree with each of the following statements.

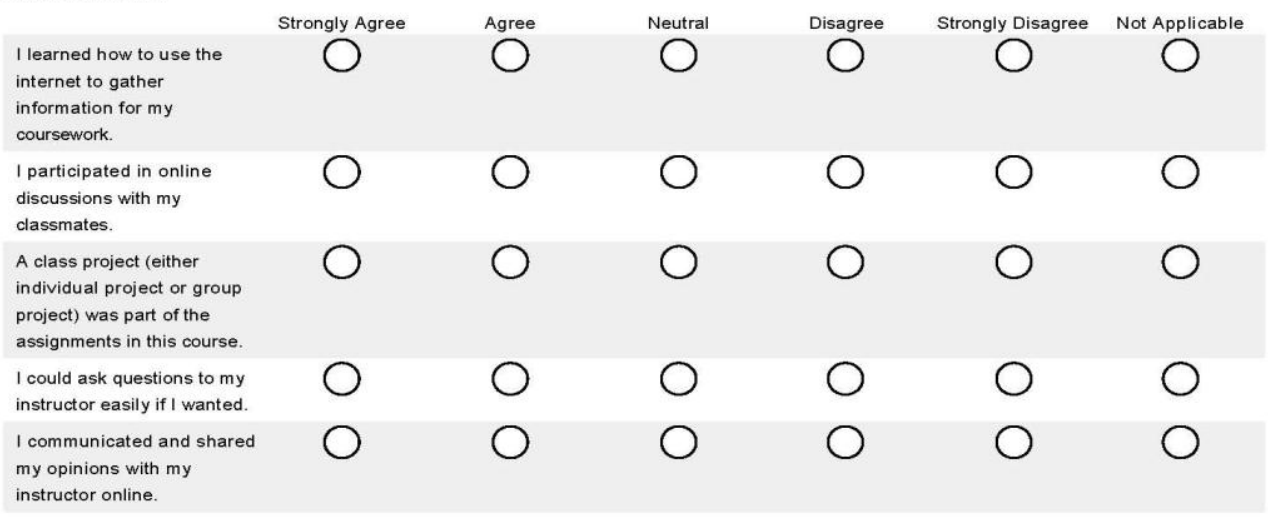


3. Please indicate the extent to how much you agree or disagree with each of the following statements.

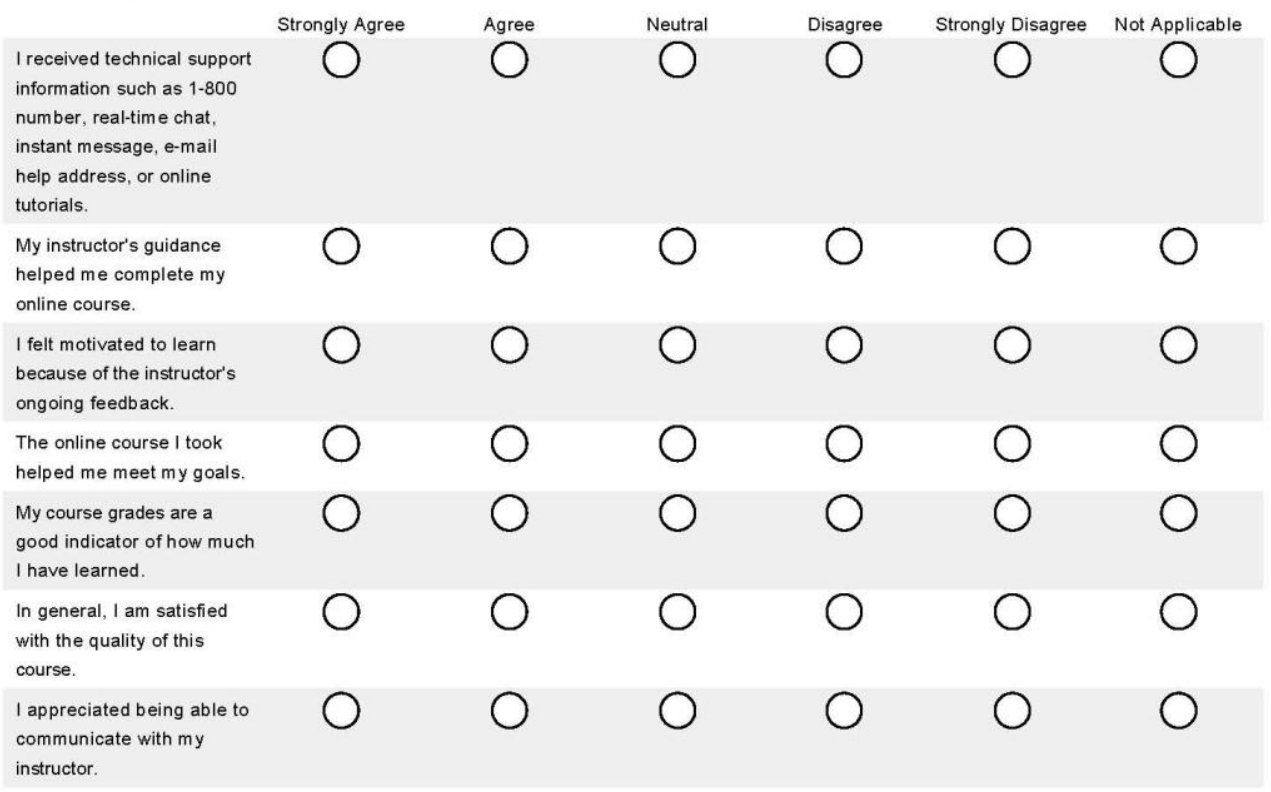




\section{2. of 6 pages}

4. Please indicate the extent to how much you agree or disagree with each of the following statements.

I appreciated being able to
communicate with $\mathrm{my}$
classmates.
$\begin{aligned} & \text { I developed a sense of } \\ & \text { community through online } \\ & \text { communications with my } \\ & \text { classmates and instructor. }\end{aligned}$
$\begin{aligned} & \text { I got to know my classmates } \\ & \text { better through the online } \\ & \text { communications. }\end{aligned}$
$\begin{aligned} & \text { Hyperlinks to resources for } \\ & \text { coursework were helpful. }\end{aligned}$
$\begin{aligned} & \text { I could easily communicate } \\ & \text { with my instructor to ask } \\ & \text { questions or share feedback. }\end{aligned}$

5. Please indicate the extent to how much you agree or disagree with each of the following statements.

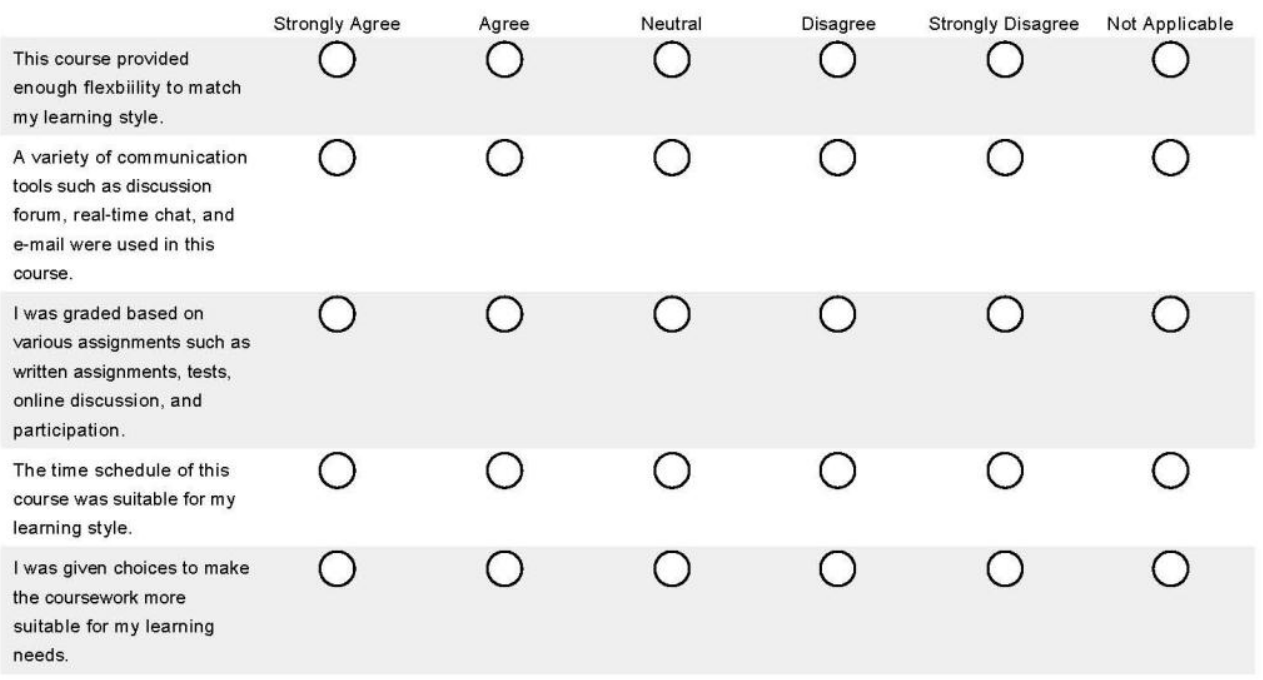




\begin{tabular}{|lll}
\hline \multicolumn{3}{l}{ 6. How satisfied were you with the following aspects of this course? } \\
Instructor \\
Course structure \\
Course content
\end{tabular}




\section{3. of 6 pages}

7. Please indicate your experience with online coursework by choosing the most appropriate answer for the statements below.

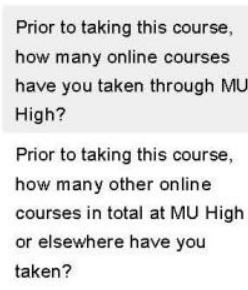

8. How comfortable were you with the idea of taking online courses before taking this one?

very uncomfortable

Uncomfortable

Somewhat uncomfortable

Somewhat comfortable

comfortable

very comfortable

9. Please indicate your parents' educational level below.

$\begin{aligned} & \text { What level of education has } \\ & \text { your mother completed? }\end{aligned}$
$\begin{aligned} & \text { What level of education has } \\ & \text { school } \\ & \text { your father completed? }\end{aligned}$

10. Overall, what letter grade would you give MU High School for the total educational experience you received?

A

в

Oc

O

OF 
11. Please feel free to include any additional comments or suggestions in the textbox below regarding any aspect of your experiences with MU High School.

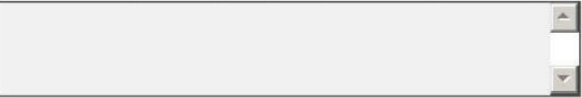

By submitting this survey you are also agreeing for your grades to be accessed for research purposes. 


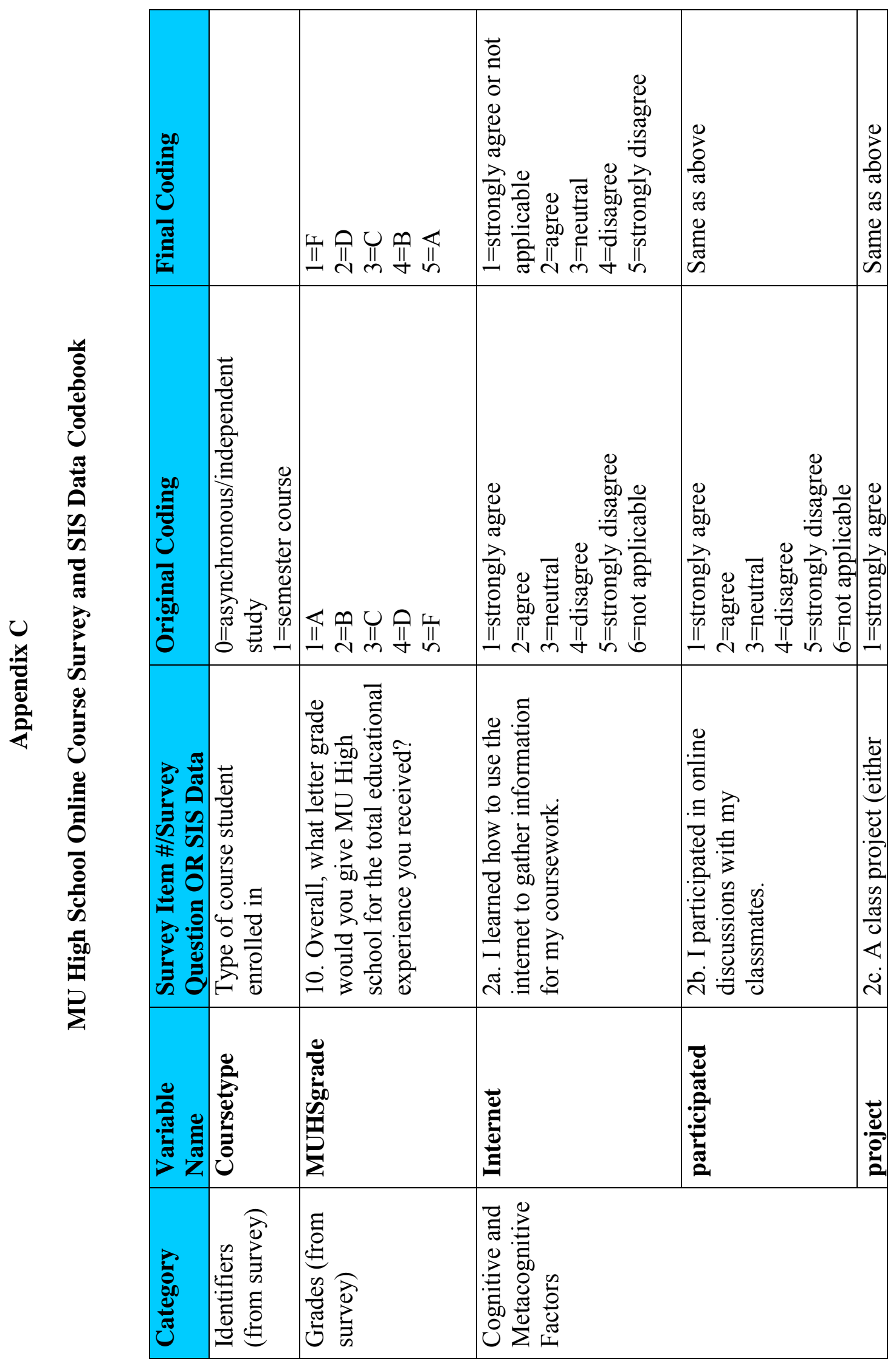




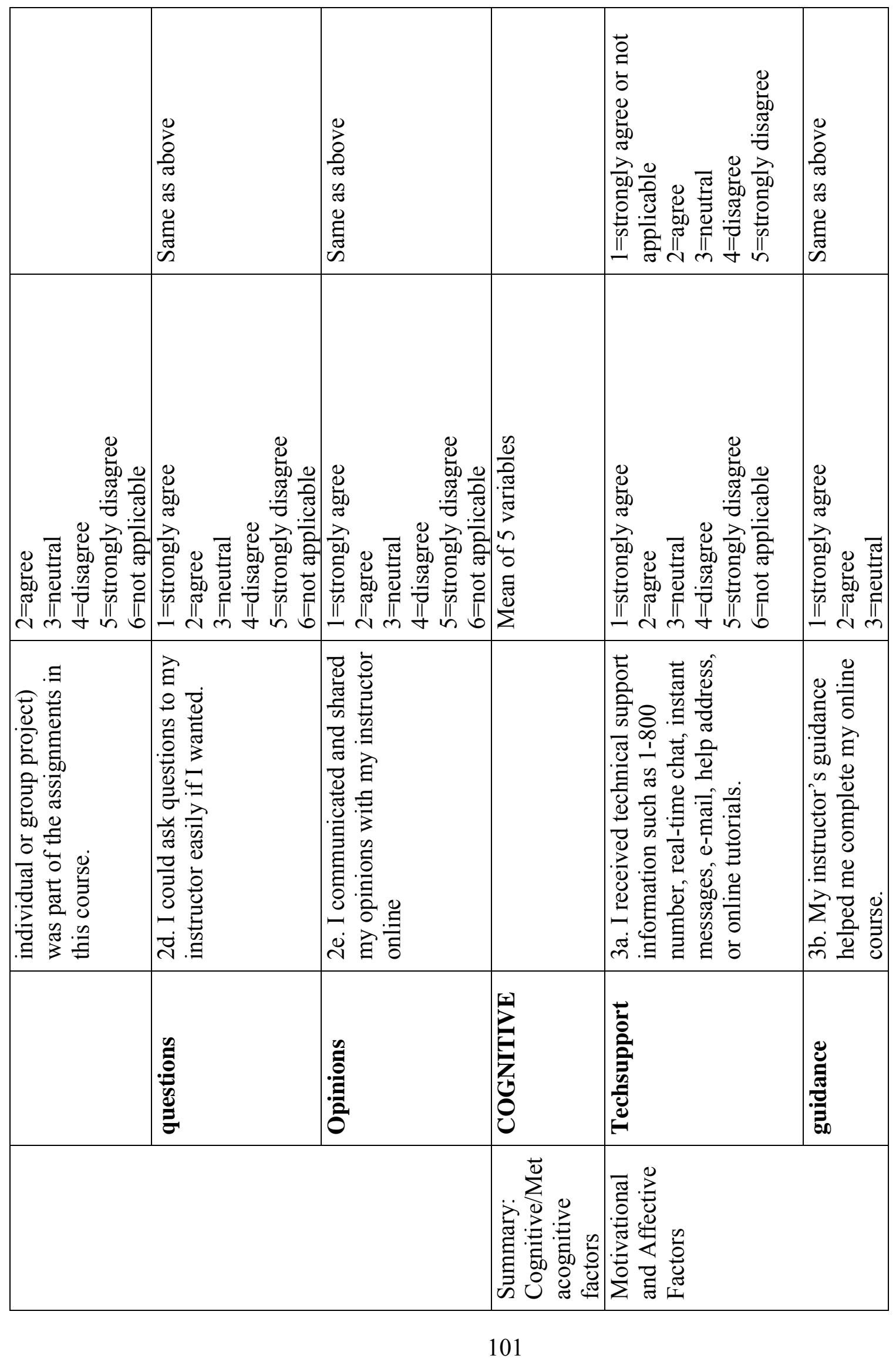




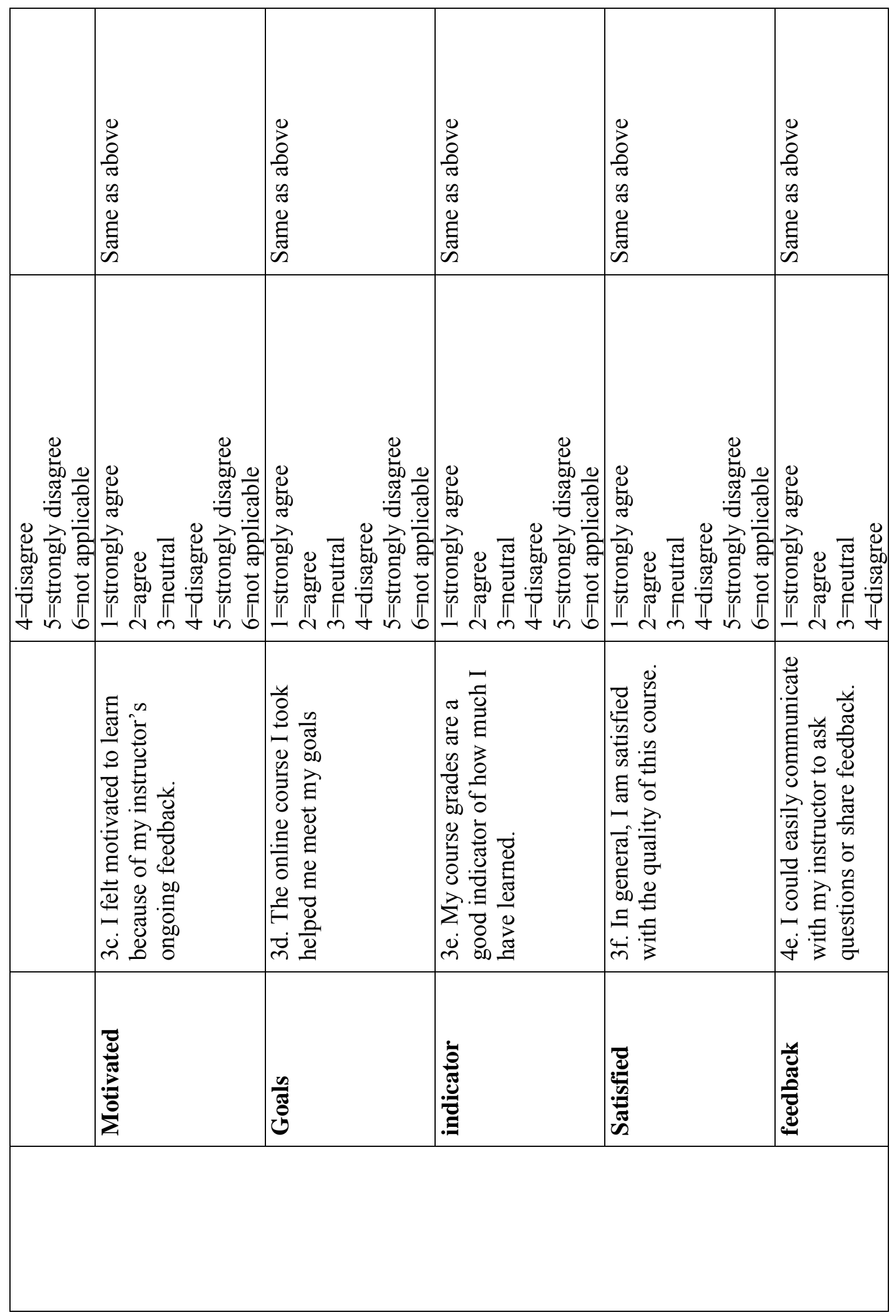




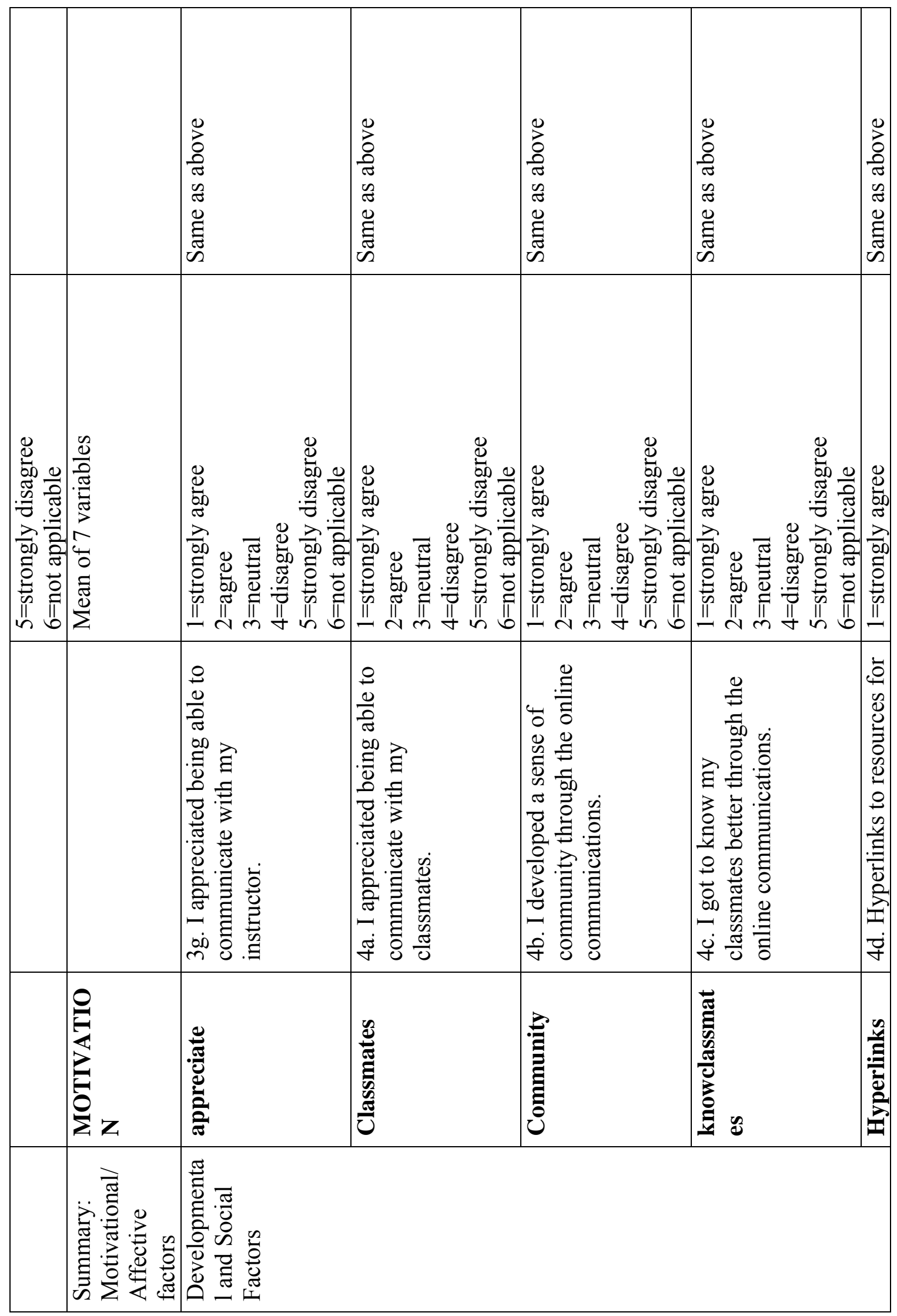




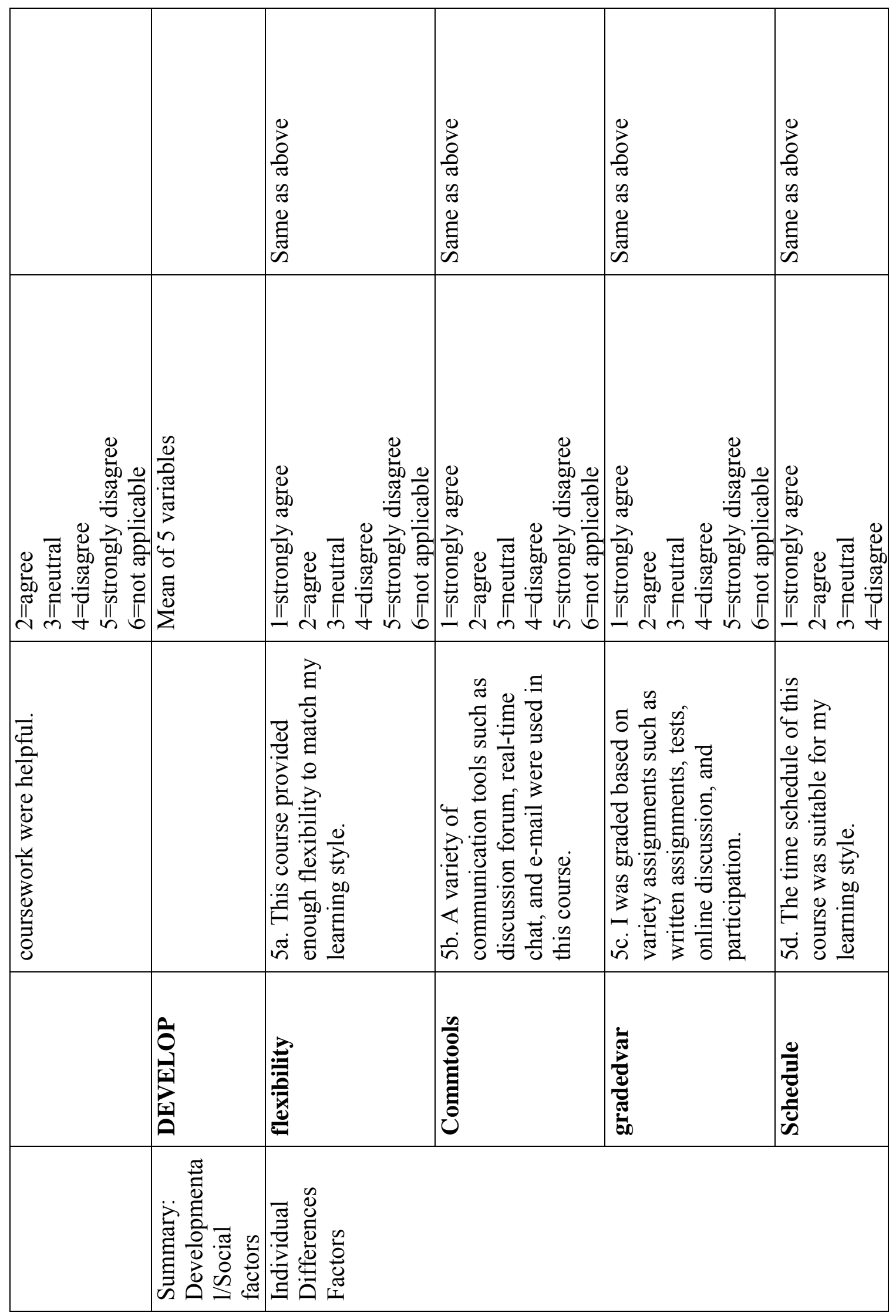




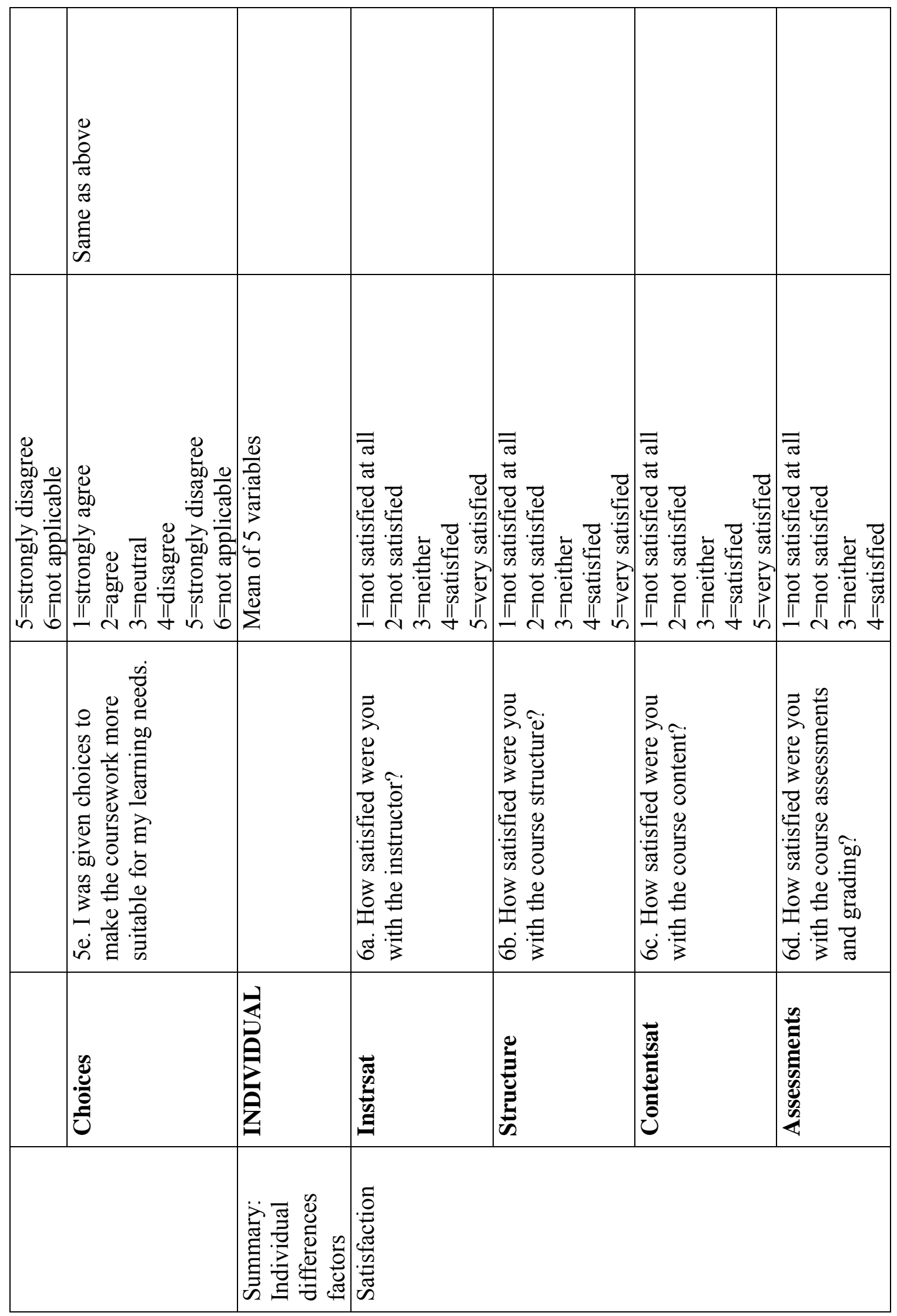




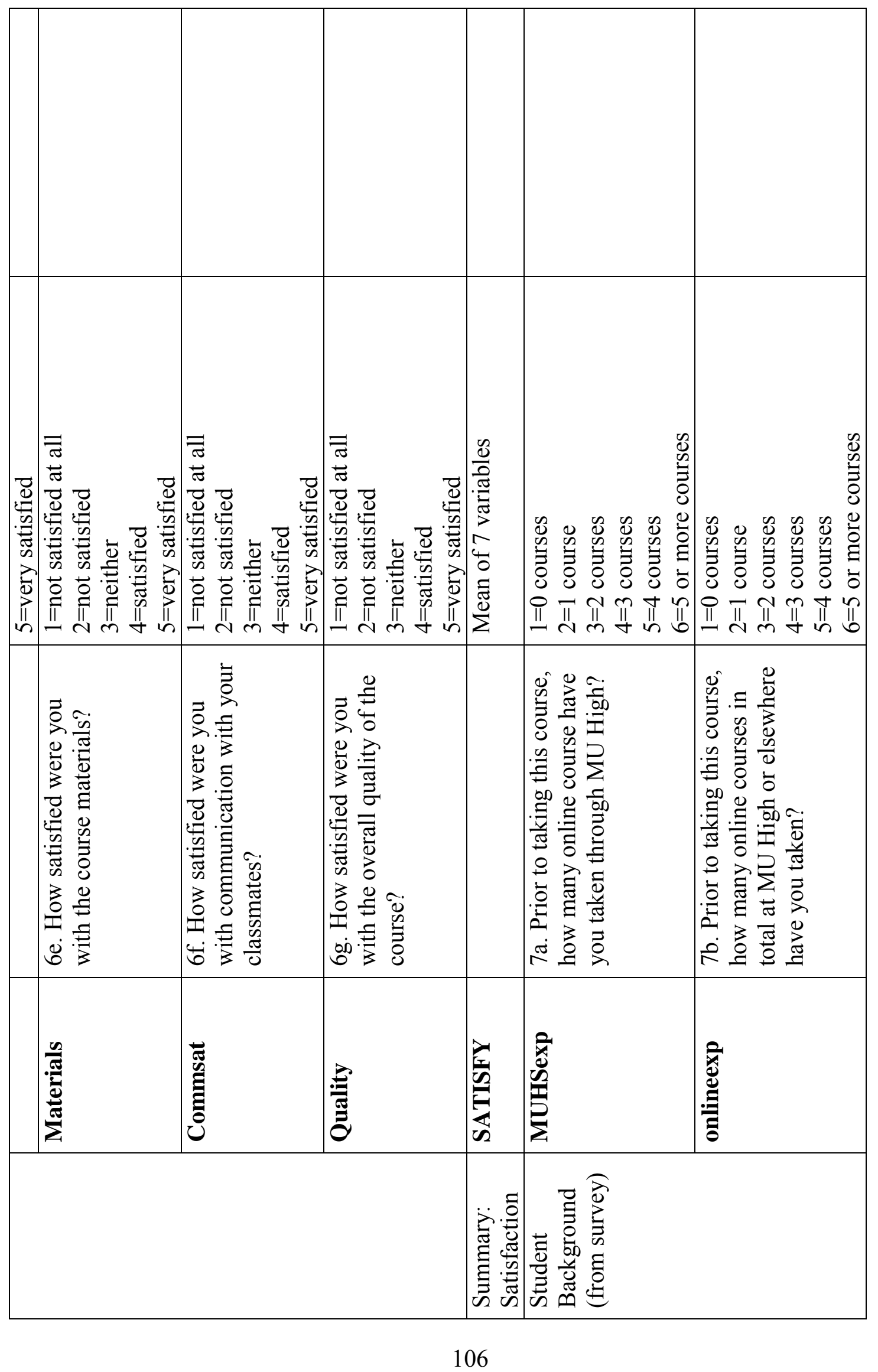




\begin{tabular}{|c|c|c|c|c|c|c|}
\hline & 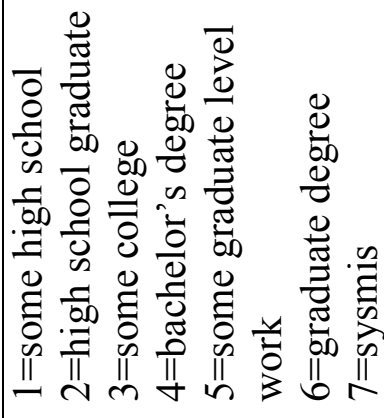 & 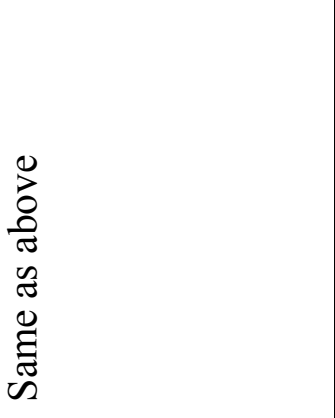 & & & & \\
\hline 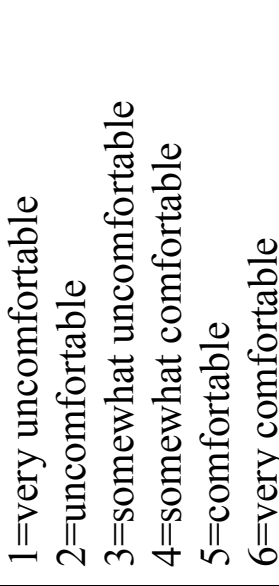 & 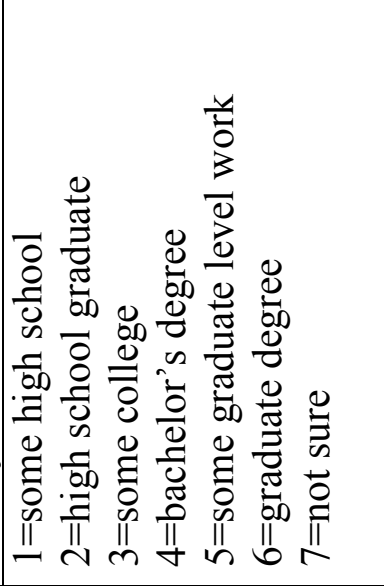 & 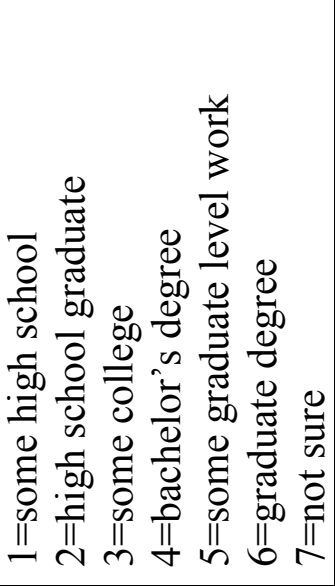 & 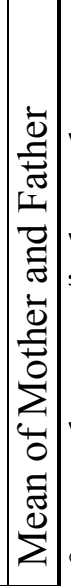 & 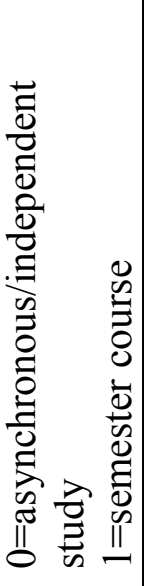 & 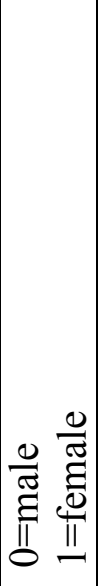 & 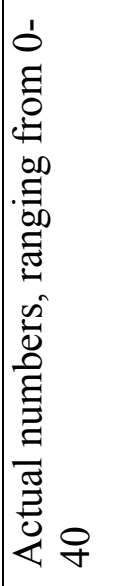 \\
\hline 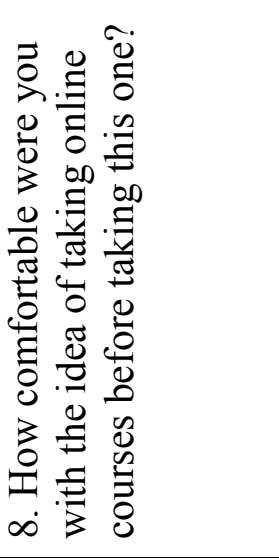 & 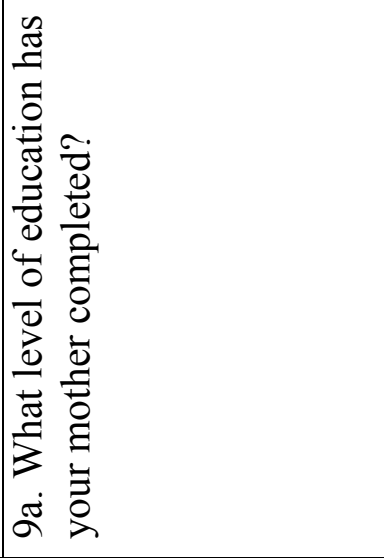 & 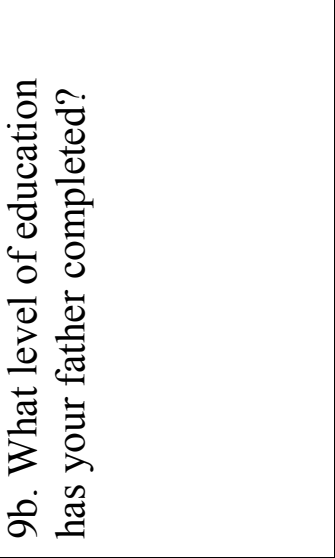 & & 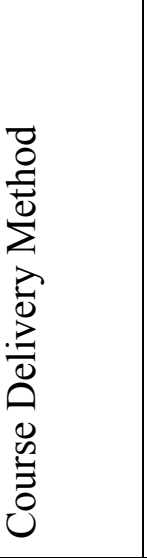 & 它 & 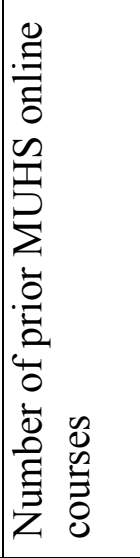 \\
\hline ن & 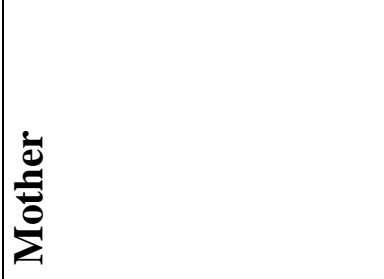 & 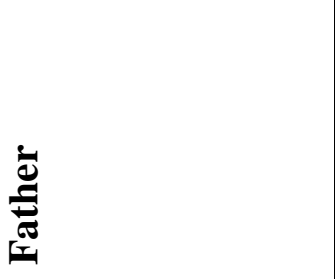 & 是 & 䓛 & 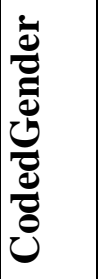 & 窇 \\
\hline & & & & \multicolumn{3}{|c|}{ 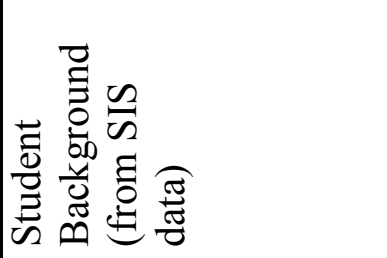 } \\
\hline
\end{tabular}




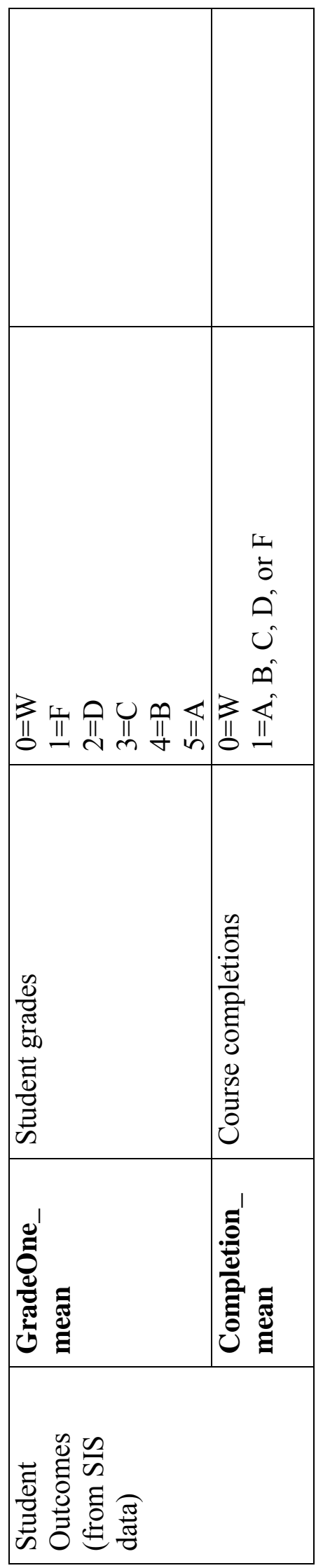




\section{VITA}

Kristi Smalley was born January 5, 1965, the middle of five children to Jim and

Lila Curnutte of Amsterdam, Missouri. She graduated from Miami R-1 school, where one literally starts Kindergarten on the north end of the building and graduates 13 years later (hopefully) from the south end. She attended and received a bachelor's degree of education from the University of Central Missouri in Warrensburg. Upon graduation she taught science at Northwest High School in Hughesville, Missouri for eight years, and another year at Hallsville, Missouri's middle school. Smalley also has earned a master's degree in science education and a specialist's degree in educational leadership from Mizzou.

She currently is principal of the University of Missouri High School in Columbia, where she has been employed for 15 years in various capacities. She feels fortunate to have always worked with such wonderful people throughout her career. She resides with her family and an assortment of pets on the outskirts of Boonville, Missouri, where she enjoys the privacy of living on four and a half acres surrounded by cows. 